San Jose State University

SJSU ScholarWorks

Master's Theses

Master's Theses and Graduate Research

1995

\title{
The use of puretone audiometry and tympanometry to identify hearing loss and middle ear disease in school age children
}

Janet Mannina

San Jose State University

Follow this and additional works at: https://scholarworks.sjsu.edu/etd_theses

\section{Recommended Citation}

Mannina, Janet, "The use of puretone audiometry and tympanometry to identify hearing loss and middle ear disease in school age children" (1995). Master's Theses. 1011.

DOI: https://doi.org/10.31979/etd.6yvu-khwg

https://scholarworks.sjsu.edu/etd_theses/1011

This Thesis is brought to you for free and open access by the Master's Theses and Graduate Research at SJSU ScholarWorks. It has been accepted for inclusion in Master's Theses by an authorized administrator of SJSU ScholarWorks. For more information, please contact scholarworks@sjsu.edu. 


\section{INFORMATION TO USERS}

This manuscript has been reproduced from the microfilm master. UMI films the text directly from the original or copy submitted. Thus, some thesis and dissertation copies are in typewriter face, while others may be from any type of computer printer.

The quality of this reproduction is dependent upon the quality of the copy submitted. Broken or indistinct print, colored or poor quality illustrations and photographs, print bleedthrough, substandard margins, and improper alignment can adversely affect reproduction.

In the unlikely event that the author did not send UMI a complete manuscript and there are missing pages, these will be noted. Also, if unauthorized copyright material had to be removed, a note will indicate the deletion.

Oversize materials (e.g., maps, drawings, charts) are reproduced by sectioning the original, beginning at the upper left-hand corner and contiming from left to right in equal sections with small overlaps. Each original is also photographed in one exposure and is included in reduced form at the back of the book.

Photographs included in the original mamuscript have been reproduced

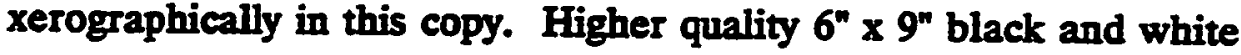
photographic prints are available for any photographs or illustrations appearing in this copy for an additional charge. Contact UMI directly to order.

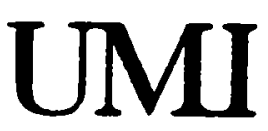

A Bell \& Howell information Company

300 North Zeeb Road. Ann Afbor. MI 48106-1346 USA

313:761-4700 800:521-0600 
THE USE OF PURETONE AUDIOMETRY AND TYMPANOMETRY

TO IDENTIFY HEARING LOSS AND MIDDLE EAR DISEASE

IN SCHOOL AGE CHILDREN

\author{
A Thesis \\ Presented to \\ The Faculty of the School of Nursing \\ San Jose State University
}

In Partial Fulfillment

of the Requirements for the Degree

Master of Science

\author{
by \\ Janet Mannina \\ May, 1995
}


UMI Number: 1374602

Copyright 1995 by Mannina, Janet Mildred

All rights reserved.

UMI Microform 1374602

Copyright 1995, by UMI Company. All rights reserved.

This microform edition is protected against unauthorized copying under Title 17, United States Code.

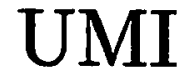

300 North Zeeb Road

Ann Arbor, MI 48103 
(C) 1995

Janet Mannina

ALL RIGHTS RESERVED 


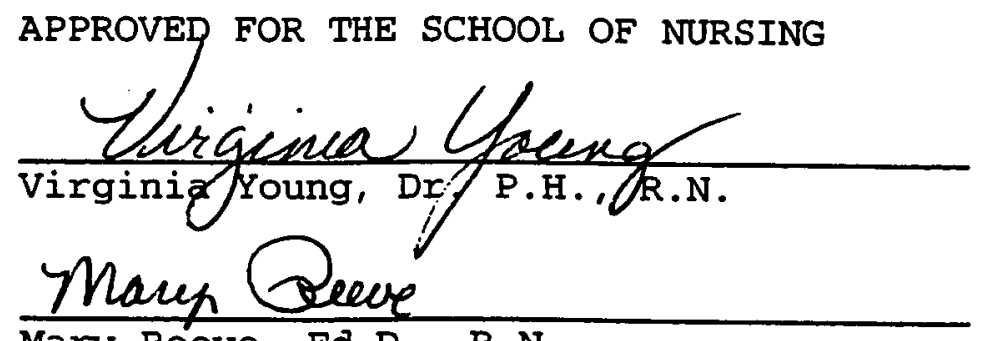

Mary Reeve, Ed.D., R.N.

Saren R. Tenit

joseph R. Ferrito, M.A., CCC-A

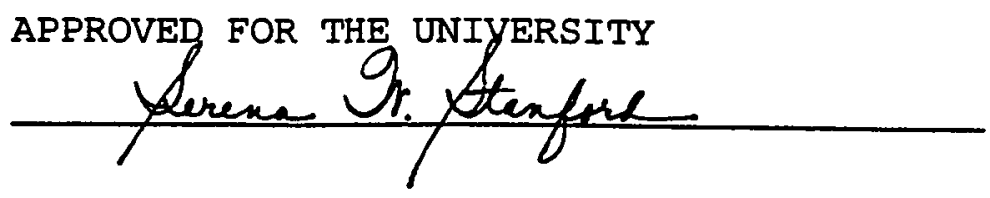




\title{
ABSTRACT \\ THE USE OF PURETONE AUDIOMETRY AND TYMPANOMETRY TO IDENTIFY HEARING LOSS AND MIDDLE EAR DISEASE IN SCHOOL AGE CHILDREN \\ by Janet Mannina
}

\begin{abstract}
This descriptive study compares the identification of hearing loss and middle ear disease using puretone threshold audiometry and tympanometry to using puretone threshold audiometry alone. Students in grades 1, 2, 5, and special day classes were tested using both methods. The data were analyzed for the number of students identified with hearing loss and middle ear disease using puretone threshold audiometry and tympanometry compared to the number of students identified using puretone threshold audiometry alone. Demographic information and differences between groups were examined. Results confirmed that more students with hearing loss and middle ear disease were identified using puretone threshold audiometry and tympanometry. Recommendations are made for school hearing screening programs.
\end{abstract}


ACKNOWLEDGEMENTS

To my family for their patience and support, to the staff and students of the Evergreen School District and to my readers,

Virginia Young, Mary Reeve, and Joseph Ferrito 
TABLE OF CONTENTS

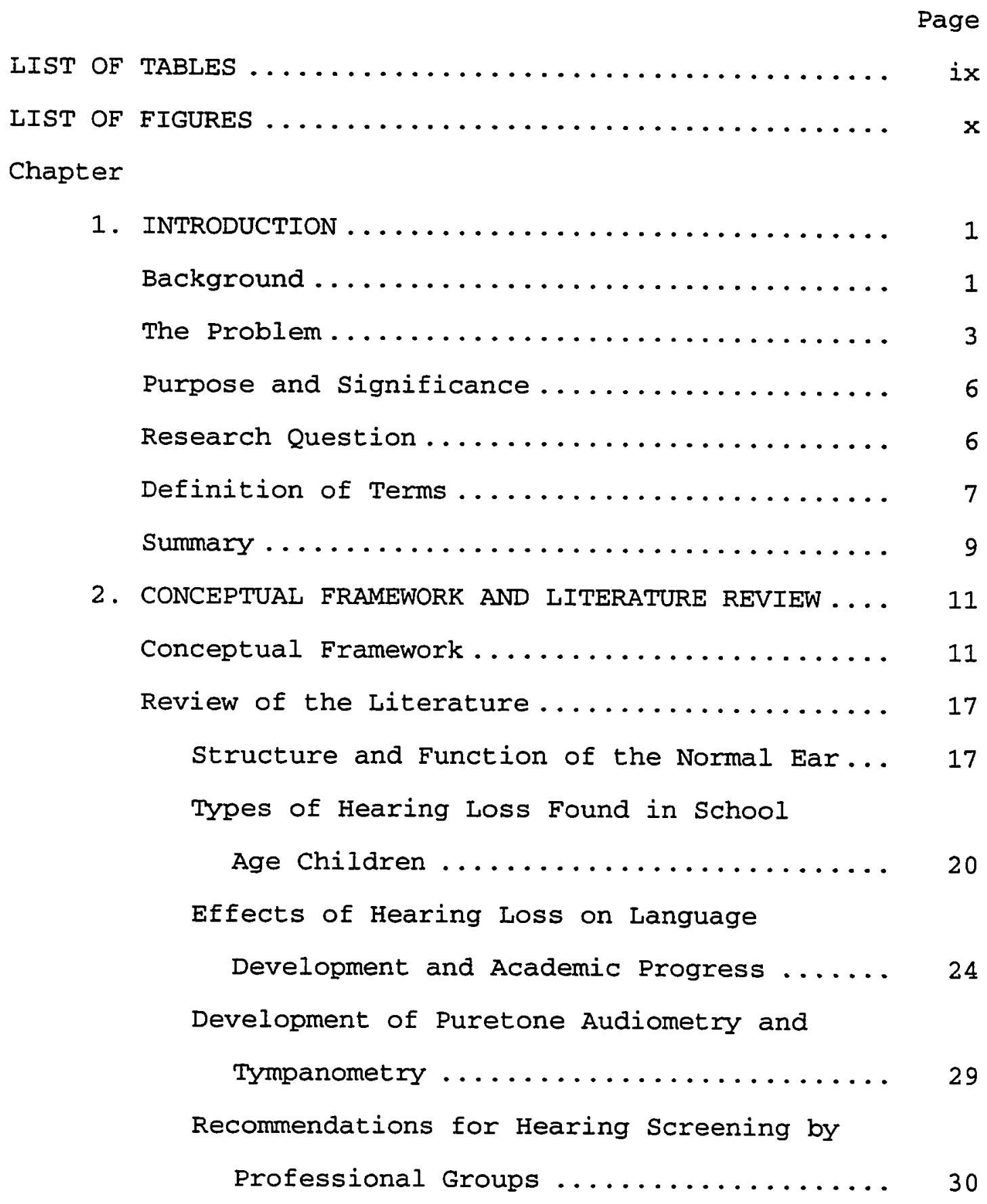

vi 
Page

Studies Employing Puretone Audiometry and Tympanometry in the school setting ..... 34

Summary ....................... 43

3. METHODOLOGY ......................... 45

Study Design .......................... 45

The Sample............................. 45

Study Approval .................... 46

Instruments $\ldots \ldots \ldots \ldots \ldots \ldots \ldots \ldots \ldots \ldots \ldots \ldots \ldots$

Testing Procedure.................. 47

Data Collection .................... 49

Analytical Procedure................. 50

4. FINDINGS AND INTERPRETATION ............. 52

Demographic Characteristics of the Sample.... 52

Results and Data Analysis ............. 53

Results by Students: Analysis......... 53

Results by Ears: Analysis............ 53

Results Related to the Research Question..... 58

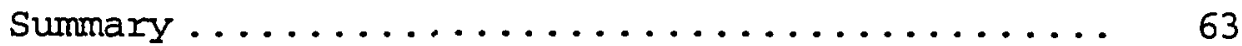

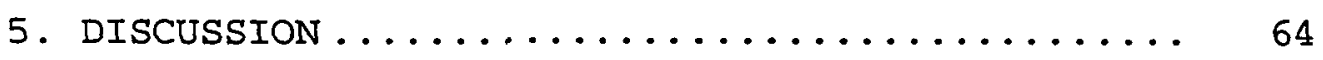

Summary of study .................... 64

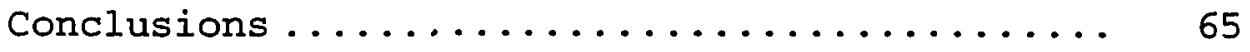

Scope and Limitations................. 69

Recommendations for Future Research ......... 71

Implications for School Nurse Practice....... 72 
Page

REFERENCES ......................... 79

$\begin{array}{lll}\text { APPENDIXES } & \text { Page }\end{array}$

A. Human Subjects Approval .............. 86

B. District Approval .................. 88

C. Agreement to Participate in Research ........ 90

D. Puretone Threshold Audiogram and

Tympanogram Form ................. 93

E. Physician Referral Form ................ 95

F. Data Collection Form C ............... 97

G. Data Collection Form D................. 99 


\section{LIST OF TABLES}

Table

Page

1. Results of First Hearing Tests Reported

by Ears According to Hearing Test Results

Categories ........................ 55

2. Results of Second Hearing Tests Reported

by Ears According to Hearing Test Results

Categories ......................... 55

3. Ears Referred from Second Puretone Threshold

Audiometry and Tympanometry Results

According to Hearing Test Results

Categories by Outcome Classifications .......

4. Students' First and Second Hearing Test Results

by Category and Outcome Classification ...... 


\section{LIST OF FIGURES}

Figure

Page

1. The Neuman Systems Model ................ 12

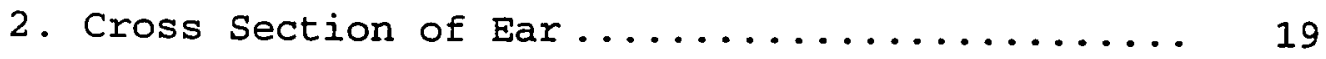




\section{INTRODUCTION}

Chapter 1

Background

It is estimated that $5 \%$ of all students between 3 and 11 years of age have a middle ear infection during each school year. Approximately one fourth have a middle ear infection with fluid in the middle ear resulting in a fluctuating hearing loss (Zanga \& Butts, 1991). These hearing losses are believed to influence academic performance, creating a speech and language barrier that interferes with communication and impedes educational progress (National Association of School Nurses [NASN], 1993).

Public schools have supported hearing conservation programs for many years. The purpose of these programs is to identify students with hearing Ioss, to refer students with a hearing loss for medical evaluation and treatment if required, and to provide adaptation of the educational program to meet the special education needs of students with hearing loss (Department of Health Services [DHS], 1989). "The key to a successful program is the early identification, treatment, and remediation of hearing losses, which prevent educational handicaps and even permanent hearing losses" (NASN, 1993, p. 1). 
Hearing conservation programs are part of the school health services program. The function of the school health services program is to support education by working to maintain and improve the physical and mental health of students. Thirty one states (61\%) mandate hearing screening programs in schools (Zanga \& Oda, 1987). Many public schools use puretone audiometry to identify hearing loss in students, a process required by the California Department of Health Services (DHS, 1989). The primary goal of puretone air conduction audiometry is to identify individuals with hearing loss. In California, the hearing screening program is mandated by the state of California (California Administrative Code [CAC] Title 17, Section 2951).

The comprehensiveness of school screening programs varies. It is estimated that tympanometry is part of the screening program in 24 states (Bess \& Humes, 1990, p. 159). In 1985, the American Speech-Language-Hearing Association (ASHA) recommended acoustic immittance (tympanometry) as a second component to puretone audiometry to identify students with middle ear disease. "The program which incorporates both puretone testing and acoustic immittance measures will be most effective in identifying individuals in need of audiological otological services" (ASHA, 1985, p. 49). Several factors have contributed to the use of tympanometry as a screening tool: (a) the prevalence of 
middle ear disease and the growing awareness of medical, psychological, and educational consequences that can result from middle ear disease; (b) the ineffectiveness of puretone audiometry in the identification of middle ear disease;

(c) the ease and rapidity of obtaining accurate information using tympanometry (Bess \& Humes, 1990, p. 173); and (d) the fact that middle ear disease may exist without hearing loss (Gimsing \& Bergholtz, 1983). The terms used for tympanometry vary in the literature. The term "acoustic immittance," which includes tympanometry as the principle test, and "acoustic reflex" have been used over the years (McDermott, 1982). The terms "impedance" and "tympanometry" are used in the literature to identify acoustic immittance. The Problem

Both conductive and sensorineural hearing loss is common in the school age population. Common causes of conductive hearing loss are middle ear disease, allergies, obstruction of the eustachian tube, and obstruction of the external ear canal. Middle ear disease may be present without hearing loss or with fluctuating hearing loss, therefore tympanometry should be included to detect midale ear disease. Common causes of sensorineural hearing loss are heredity, infections, noise-induced damage to the inner ear and auditory nerve, and toxic effects of drugs. Downs stated that 30 studies involving 3,500 subjects have shown a 
consistent association between fluctuating hearing loss and decreased learning skills (Bluestone et al., 1983, p. 643).

In hearing conservation programs the hearing screening is done by the school nurse or a school audiometrist under contract with the school district. If a school audiometrist is hired to do the screening, the school nurse does any additional screening required, makes referrals for medical evaluation, and assists the family in securing an ear examination and completing treatment when a problem is found. The hearing screening program is expensive, and the program requires a significant amount of school health services time.

Puretone audiometry is subjective, requiring the comprehension and cooperation of the student. Tympanometry is objective and does not depend on the subject's perception or response to the sound (Paradise \& Smith, 1979).

One of the problems with using puretone audiometry alone in school screening programs is the number of false positives, results that indicate a problem when none exists. The accuracy of audiometry is stated in the number of subjects correctly identified. Screening programs result in a number of false positives, subjects who fail the tests but have normal ears. False negatives, subjects who pass the tests but have a problem, are also found (Wilson \& Walton, 1974). 
A good screening test produces valid results. It must have reliability, the consistency with which a test measures what it is designed to measure. A test repeated on the same subject within a short interval will yield the same results when it is reliable. It must have validity, the consistency with which the test results agree with the presence or absence of a problem. Validity is measured by sensitivity and specificity of the test. The sensitivity is the accuracy with which a test identifies subjects with disease. The specificity is the accuracy with which a test identifies subjects without disease (Paradise \& Smith, 1979).

False positives waste the time of the school nurse and the parents. Referrals based on false positives require an expensive, unnecessary ear examination. Several researchers have demonstrated that hearing evaluations combining puretone threshold audiometry and tympanometry provide an effective testing protocol for identifying hearing loss and middle ear disease in school children (Beery, Bluestone \& Cantekin, 1975; Bonny, 1989; Fitzzaland \& Zink, 1984; Gimsing \& Bergholtz, 1983; Holtby \& Forster, 1992; Renvall \& Holmquist, 1976; Renvall \& Lindén, 1980; Roush \& Tait, 1985; West, 1987). No studies done by school nurses using the proposed screening protocol were found in the literature. During this study the researcher evaluated the combined testing process to discover whether or not puretone 
threshold audiometry and tympanometry together identify more students with hearing loss and middle ear disease.

Purpose and Significance

The purpose of the study was to compare the difference between the number of students who were identified with hearing loss and middle ear disease using the study protocol employing both puretone threshold audiometry and tympanometry and the number of students who were identified using the DHS required puretone threshold audiometry screening protocol. The anticipated outcome was that using a combination of the two methods improves the identification of hearing loss and middle ear disease. Students were referred for medical care when needed, thereby avoiding potential learning problems. The study results have the potential for improving the health services program and improving the health and academic achievement of students prone to middle ear disease.

Research Question

There was one major research question asked in this study. It was: "Does puretone threshold audiometry and tympanometry identify more students with hearing loss and middle ear disease than puretone threshold audiometry alone?" 
Definition of Terms

1. Air conduction audiometry is a technique to measure hearing using sound waves conducted by air via earphones (DHS, 1989).

2. ANSI refers to American National Standards Institute (DHS, 1989). It is one of the official bodies which establishes norms for the definition of hearing characteristics and performance criteria (Ballantyne, 1990).

3. Audiogram is a graphic representation of an individual's hearing threshold level (NASN, 1993).

4. Bone conduction audiometry is the measurement of an individual's hearing threshold level with sound conducted to the inner ear through the cranial bones (DHS, 1989, Martin, 1986).

5. Decibel $(d B)$ is a unit of measurement of intensity used in audiometrics (NASN, 1993).

6. Erequency is the unit of measurement denoting the number of vibrations in cycles per second (Hz) (NASN, 1993).

7. Elat tympanogram is a graphic representation of poor middle ear compliance. It lacks a peak and appears flat due to little or no mobility of the tympanic membrane. It is also known as a Type B tympanogram (McDermott, 1982).

8. Hearing screening is the application of hearing test procedures to an individual for the purpose of 
identifying those individuals whose hearing is below the normal range (DHS, 1989).

9. Hertz $(\mathrm{Hz})$ is the international measurement unit of cycles per second (NASN, 1993).

10. Otoscope is a device with a light and speculum on the end used for examination of the external ear canal and the tympanis membrane (Martin, 1986).

11. Puretone audiometry is a method of hearing screening that utilizes pure tones of various frequencies and intensities (NASN, 1993).

12. School audiometrist is an individual trained in the skills needed to administer basic hearing tests and certified by the state of California (DHS, 1989).

13. Threshold of hearing is defined as the minimal hearing level at which an individual is able to respond to a tone at least $50 \%$ of the time (DHS, 1989).

14. Tympanic membrane (eardrum) is a thin membrane located between the external auditory canal and the middle ear. It responds to sound waves and sets the bones of the middle ear in motion (NASN, 1993).

15. Ivmpanearam is the graphic representation of middle ear compliance under changing pressure conditions (Ballantyne, 1990). 
16. Tympanometry is an objective method of testing the integrity and function of the midale ear system and is also known as impedance or acoustic immittance (NASN, 1993).

Summary

Middle ear disease occurs in about $5 \%$ of the school population (Zanga \& Butts, 1991). Hearing loss is believed to influence academic progress, creating a speech and language barrier that interferes with commus:1ation and impedes educational progress (NASN, 1993). The purpose of a hearing screening program is to identify students with hearing loss. The hearing screening program in the public schools mandated by the state of California uses puretone audiometry alone. Tympanometry, an objective measure of the function of the middle ear, can identify middle ear disease with or without hearing loss. Puretone audiometry is effective in identifying hearing loss. Several researchers have demonstrated that puretone audiometry and tympanometry combined provide a better protocol for identifying hearing loss and middle ear disease that may become educationally handicapping (Beery, Bluestone \& Catekin, 1975; Bonny, 1989; FitzZaland \& Zink, 1984; Gimsing \& Bergholtz, 1983; Holtby \& Forster, 1992; Renvall \& Holmquist, 1976; Renvall \& Lindén, 1980; Roush \& Tait, 1985; West, 1987). Older studies are referenced in the literature review since this issue has 
been studied over the last 25 years and these older studies are considered classics. 


\section{Chapter 2}

\section{CONCEPTUAL FRAMEWORK AND LITERATURE REVIEW}

Conceptual Framework

Betty Neuman's systems model with its emphasis on wellness was selected as the framework for this study (Figure 1). Health or wellness is defined as optimal system stability. Health is placed on a wellness-illness continuum with energy continuously flowing between the client and the environment (Neuman, 1989, p. 33). When the individual's needs are met and more energy is generated than required, the individual is on the wellness side of the continuum, but when an individual's needs are not met and more energy is required than is generated, the individual moves toward the illness side of the continuum (Fawcett, 1989, p. 177).

The client, an open system, is composed of an interrelationship between physiological, psychological, sociocultural, developmental, and spiritual variables (Fawcett, 1989, p. 172). Each variable has a wide range of interactive styles and potentials (Neuman, 1989, p. 29).

The client is composed of a central core structure consisting of basic survival factors. The central core contains the unique characteristics of the individual: genetic features, ego structure, strength and weakness of body systems, and cognitive ability (Neuman, 1989, p. 27). 


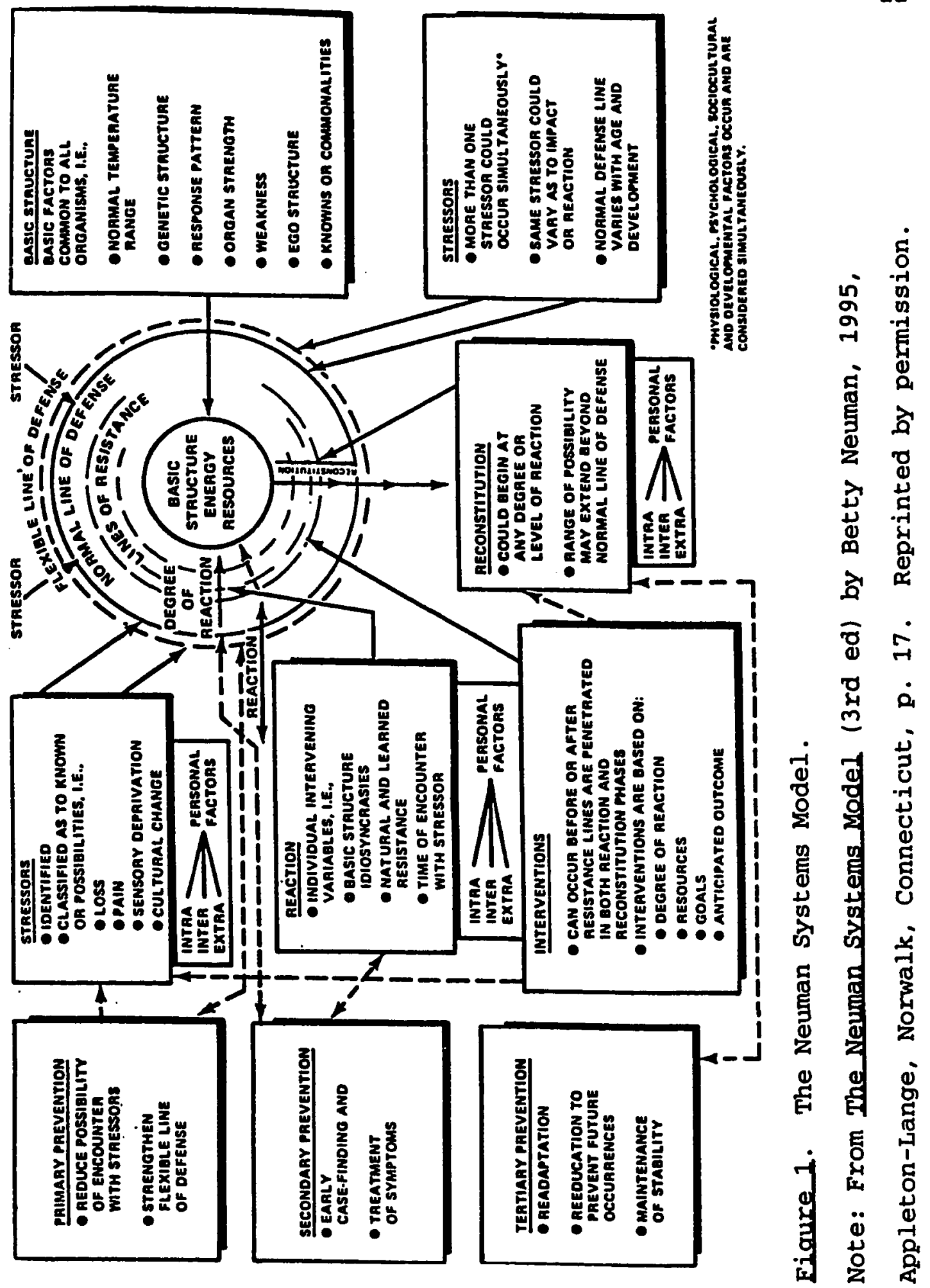


Several lines of defense and resistance protect the client from environmental stressors and maintain system stability. Elements specific to the five client variables are found in all lines of defense and resistance. The normal line of defense represents a state of wellness or stability. This state is the one maintained by the client over time by using successful coping skills and lifestyle patterns and is the standard against which deviations from normal can be determined. Outside the client's normal line of defense, Neuman (1989) identifies the flexible line of defense which buffers stressors from breaking through the solid line of defense, causing symptomatology (p. 28). Internal lines of resistance are found closest to the central core and contain internal factors that protect the client's basic structure, such as the immune system, and maintain system stability (Neuman, 1989, p. 30).

Neuman (1989) defines the environment as all internal and external factors influencing and being influenced by the client (p. 48). The relationship between the client and the environment is open, dynamic, and continuously changing (p. 31). Stressors are environmental forces, internal and external, that may alter the stability of the system. Neuman defines stressors as intrapersonal (forces within the individual), interpersonal (forces between individuals), and extrapersonal (forces outside the individual) (p. 70). 
Neuman (1989) views nursing as a unique profession concerned with all the variables affecting an individual's response to stress (p. 72). Nursing interventions retain, attain, and maintain optimum health or system stability. Nursing interventions are divided into three prevention levels: primary level of prevention, secondary level of prevention, and tertiary level of prevention (p. 35). Primary prevention activities prevent disease before it occurs. Secondary prevention activities provide early diagnosis and treatment of disease. Tertiary prevention activities limit progress of disease and provide rehabilitation (Swanson \& Albrecht, 1993, p. 7).

At the primary level of prevention, the client's normal line of defense is protected by strengthening the flexible line of defense to retain wellness. At this level a stressor is suspected or has been identified, but a reaction to the stressor has not yet occurred (Fawcett, 1989, p. 178). Health promotion at this level prevents stress and reduces risk factors (Neuman, 1989, p. 35). In this study, the application at the primary level of prevention is to use health education to teach the students and parents to maintain a healthful lifestyle to resist disease. Adequate patterns of diet, rest, exercise, and coping skills must be developed to conserve energy and build resistance to disease. Upper respiratory infections and allergies are 
known stressors to the auditory system and must be prevented.

At the secondary level of prevention, the system is protected by strengthening the internal lines of resistance, reducing the reaction to stressors which have entered the system and produced symptoms of illness. Appropriate treatment is needed to conserve energy and attain client stability (Neuman, 1989, p. 36). In this study, the application at the secondary level of prevention is to conduct hearing screening programs to identify hearing loss and middle ear disease. Symptoms are identified and parents are counseled regarding effective treatment of the disorder. Teachers are notified of the student's limitations, reducing the student's stress and conserving the student's energy to attain wellness.

At the tertiary level of prevention, the client system is protected while it reconstitutes or returns to normal following treatment. To prevent further reactions to stress, the interventions support existing client strengths and conserve the client's energy. This level represents a state of adjustment to stressors and requires optimal use of existing resources to maintain stability and wellness. The tertiary level of prevention leads back to the primary level of prevention, completing a cycle (Neuman, 1989, p. 37). In this study, the application at the tertiary level of 
prevention occurs with treatment for ear disorders. The nurse follows the case until the problem is resolved. The nurse counsels the student to identify and avoid the stressor which created the problem. Classroom modifications may have to be made if the hearing loss persists or is permanent. The student with a severe hearing loss needs rehabilitation. The nurse is a participant in the development and implementation of an individual education plan (IEP). The nurse must follow up when hearing aids have been prescribed. The nurse assists the student to adjust and to avoid additional stressors, thus maximizing the benefits from the IEP.

The Neuman Systems Model places emphasis on wellness, and the client is viewed as a holistic being. When assessment is done and interventions are planned, all client variables must be included: physiological, psychological, sociocultural, developmental, and spiritual. The client and the environment are in continuous interaction, affecting and being affected by each other. Nursing interventions are provided at the primary level of prevention to retain system stability, at the secondary level of prevention to attain system stability, and at the tertiary level of prevention to maintain system stability (Neuman, 1989, p. 35). 
Review of the Literature

The review of literature is divided into six sections. The first section reviews the structure and function of the normal ear. The second section reviews the types of hearing loss found in school age children. The third section reviews the effect of hearing loss on language development and academic progress. The fourth section reviews the development of puretone audiometry and tympanometry. The fifth section reviews recommendations for hearing screening by professional groups. The sixth section reviews studies employing puretone audiometry and tympanometry in the school setting.

\section{Structure and Function of the Normal Ear}

The ear receives sound waves and sends them to the brain for processing. The four major components of the auditory system are the outer ear, the middle ear, the inner ear, and the auditory nervous system (DHS, 1989).

The parts of the outer ear are the pinna, which is visible, and the external auditory canal, which conducts sounds and amplifies high frequency sounds to the tympanic membrane. The outer third of the canal has hair follicles and glands producing cerumen to protect the tympanic membrane from foreign objects (Bess \& Humes, 1990, p. 39).

The middle ear is an air filled cavity, beginning at the tympanic membrane and ending at the oval window of the 
inner ear. The cavity contains a series of three bones: the malleus contacting the tympanic membrane; the incus; and the stapes, connected to the membranous oval window of the inner ear. The function of the middle ear is to amplify and transfer sound vibrations from the tympanic membrane through the bones of the middle ear to the fluid in the inner ear. The anterior of the middle ear cavity has an opening into the eustachian tube, connecting it to the nasopharynx (Bess \& Humes, 1990, p. 42). The eustachian tube equalizes the air pressure on both sides of the tympanic membrane and permits drainage of fluid from the midale ear. The eustachian tube, not fully developed in the young child, is short and in a more horizontal position allowing bacteria from the nasopharynx to enter the middle ear. These factors account for a higher percentage of ear infections in the young child (Fireman, 1987).

The inner ear is composed of two sensory organs: the cochlear and vestibular organs. The vestibular sensory organ contains the semicircular canals which maintain balance and posture. The cochlear sensory organ is the organ of hearing and contains the organ of corti. The cochlea consists of three fluid filled chambers: scala vestibuli, scala media, and scala tympani. The organ of Corti, located in the scala media, contains thousands of sensory receptors called hair cells. The bones of the 


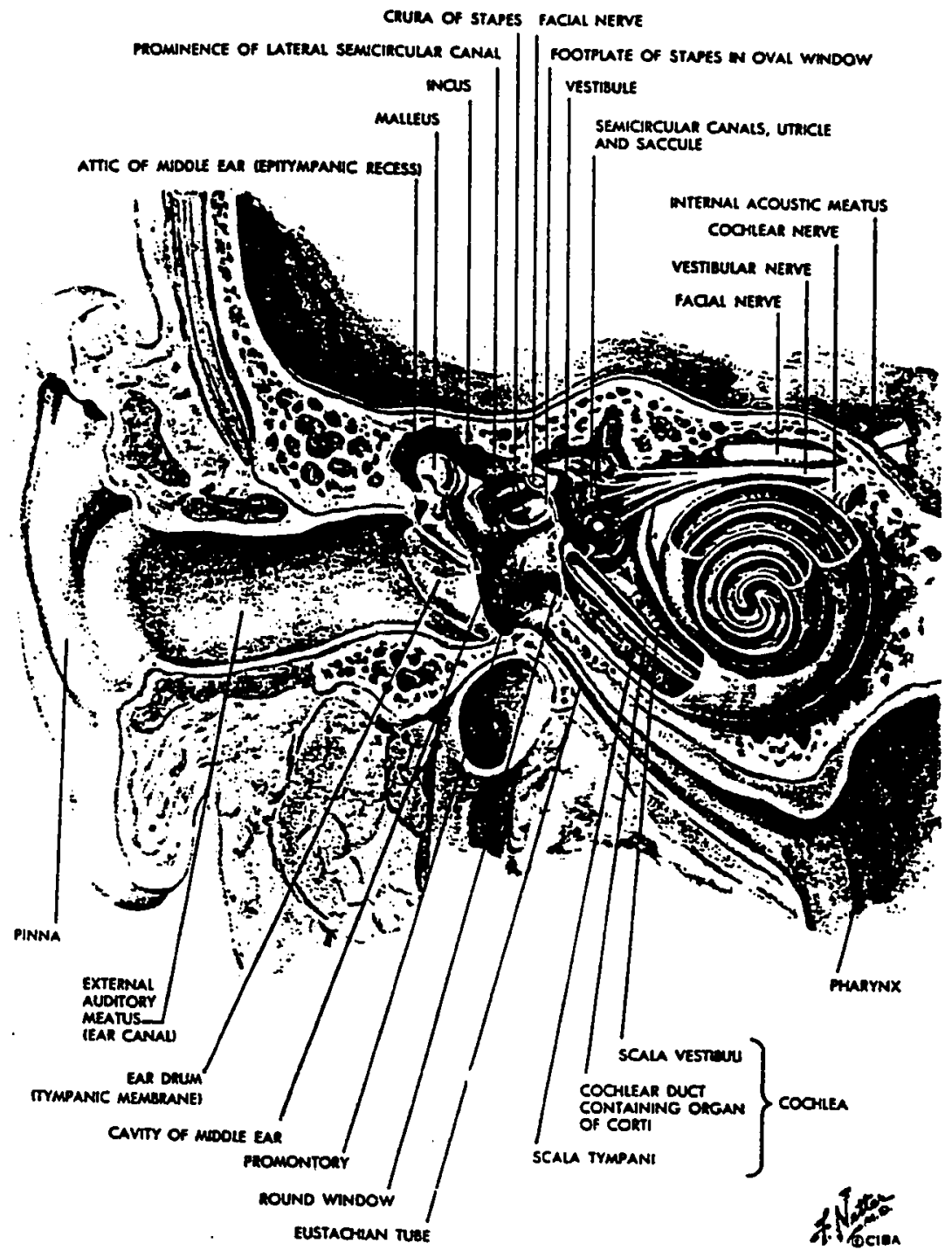

Eiqure 2. Cross Section of Ear.

Note: From clinical symposia, Volume 14, No. 1, Plate Number 1, p. 42. Reprinted by permission. 
middle ear transmit the vibrating sound to the oval window, moving the fluid in the inner ear. Mechanical vibrations are converted into electrical energy by the hair cells (Northern \& Downs, 1991, p. 55).

The auditory nervous system is composed of the auditory nerve and its pathways to the brain. The nerve impulses travel along the auditory nerve, through the brain stem to the temporal lobe of the cerebrum for processing (Northern \& Downs, 1991, p. 55).

Types of Hearing Loss Found in School Age Children

Types of hearing loss commonly found in school age children are sensorineural hearing loss, conductive hearing loss, and mixed hearing loss. A sensorineural hearing loss is caused by a dysfunction of the inner ear or the auditory nerve and occurs less frequently than a conductive hearing loss. The hearing loss is generally greater at the higher frequencies $(3000 \mathrm{~Hz}$ through $6000 \mathrm{~Hz})$, with hearing in the lower frequencies at normal range in some students and diminished hearing at all frequencies in other students (DHS, 1989). Sounds conducted by air and bone conduction are nearly the same and are not heard at normal thresholds. The tympanic membrane appears normal upon physical examination. Common causes of sensorineural hearing loss found in school age children are heredity, infections (especially meningitis), toxic effects of drugs, and 
exposure to loud sounds. This type of hearing loss is almost always irreversible but should be medically evaluated to determine the cause (Northern \& Downs, 1991, p. 11).

A conductive hearing loss is due to a dysfunction found in either the outer or the middle ear that interferes with the transmission of sound from the external ear to the inner ear. The student with a conductive hearing loss usually has the same degree of hearing at all sound frequencies and can understand speech when the volume is increased (NASN, 1993). The audiogram of a student who has middle ear disease with accompanying effusion or fluid is usually flat through the speech frequencies $(500 \mathrm{~Hz}$ through $2000 \mathrm{~Hz}$ ), and the loss is approximately $27.6 \mathrm{~dB}$ (Bluestone et al., 1983, p. 640). Bone conducted sounds to the inner ear are heard at normal sound thresholds. Conductive hearing loss is usually medically or surgically treatable (Northern \& Downs, 1991, p. 10).

Some conductive hearing losses are caused by obstruction in the outer canal due to excessive cerumen (earwax) or foreign objects. Persons who produce excessive cerumen or have an inadequate self cleaning mechanism in the outer ear will experience blockage of the ear canal, with resulting hearing loss. The cause of the obstruction must be removed by a medical doctor (Northern \& Downs, 1991, p. 63). 
A mixed hearing loss is a combination of a conductive loss and a sensorineural loss (DHS, 1989). These students must be screened routinely even though the sensorineural loss is known, since middle ear disease can occur at any time and often is not recognized.

One of the most common diseases of childhood is otitis media, inflammation of the midale ear. It is the most common cause of conductive hearing loss. Middle ear effusion is the liquid in the middle ear cavity resulting from otitis media, and it interferes with the transmission of sound to the inner ear (Northern \& Downs, 1991, p. 65).

Otitis media is more common during the first 2 years of 1ife, decreasing in incidence with the increase in age (Northern \& Downs, 1991, p. 65). At the Otitis Media Workshop in Chicago in 1982, Bess reported that studies in the United States and Scandinavia indicate that up to $28 \%$ of children without symptoms have middle ear effusion (Bluestone et al., 1983, p. 640). Otitis media occurs more frequently in boys than girls (Northern \& Downs, 1991, p. 65). Otitis media occurs more often during winter months than during summer months and is related to seasonal upper respiratory infections (Northern \& Downs, 1991, p. 65). Otitis media may or may not be infectious in origin. Classification is according to duration: acute otitis media lasts as long as 3 weeks while chronic otitis media lasts 
longer than 8 weeks. Otitis media is also classified by the presence or lack of fluid, and when fluid is present it is classified according to the type of fluid: serous (thin), purulent (pus), or mucoid (thick). The most common type of fluid seen in school age children is chronic serous otitis media (Northern \& Downs, 1991, p. 67).

Otitis media may be present without symptoms and can be found during the routine hearing screening at school or during a routine physical examination. Otitis media may be present with or without a hearing loss. Acute otitis media is accompanied by symptoms of pain, fever and a red, bulging eardrum (Giebink, 1988).

Fiellau-Nikolajsen (1983) studied the duration and course of middle ear disease with effusion (MEE). During the 6 month study, $50 \%$ of the subjects with MEE recovered spontaneously. Thirty two percent of the subjects had persistent MEE and $18 \%$ had fluctuating MEE over the 6 months. Spontaneous recovery rarely occurred when MEE was present for over 3 months.

Eustachian tube obstruction is believed to be a common cause of middle ear disease with effusion. The eustachian tube connects the middle ear to the nasopharynx, equalizes air pressure in the middle ear, and permits drainage from the middle ear. When the eustachian tube becomes obstructed due to infection, allergy, or enlarged adenoidal tissue, a 
negative pressure is created in the middle ear, drawing fluid from the mucous lining into the middle ear cavity (Bess \& Humes, 1990, p. 127).

Treatment depends on the cause of middle ear disease. Infections are treated with an antibiotic, usually ampicillin or antibiotics specific to the infecting agent. Antihistamines may be prescribed for obstruction of the eustachian tube caused by an allergic response (Bess \& Humes, 1990, p. 130). If the student does not respond to medical treatment, the surgical insertion of a tympanostomy tube into the tympanic membrane under general anesthesia can provide pressure equalization and drainage from the middle ear cavity (Bluestone et al., 1986, p. 59).

Effects of Hearing Loss on Lanquage Development and Academic Progress

Students with middle ear disease have difficulty at school. Every student referred to the student study team for evaluation of academic progress is referred to the school nurse for a health assessment. This assessment includes a vision and hearing screening, and some of these students are identified with hearing problems and as having a history of middle ear disease.

Does middle ear disease with hearing loss cause deficits in language development and have an adverse effect on academic progress? The effect of otitis media on 
language development and academic progress has divided professionals into two groups with opposing views. One view is that otitis media has a detrimental effect on language and academic progress since inconsistent auditory reception creates problems for children with mild to moderate hearing loss. The opposing view is that otitis media has no effect on language development and academic progress because episodes are of short duration and periods of normal hearing exist between episodes (Northern \& Downs, 1991, p. 19).

Studies have been done over the past decade to substantiate the view that otitis media has a detrimental effect on language development and academic progress. Zinkus, Gottlieb, and Schapiro (1978) conducted a study on 40 subjects, 6 through 11 years of age, to determine the effect otitis media with hearing loss had on language and academic achievement. All subjects had confirmed otitis media during the first 3 years of life requiring myringotomy, a surgical incision made in the tympanic membrane. They were referred for academic underachievement and were evaluated by medical, developmental, psychological, and educational tests. Results suggest an association between severe otitis media and impaired auditory processing and language development. The subjects had difficulty with verbal tasks that required auditory processing and the integration of verbal and auditory skills. Although the 
middle ear disease had completely resolved, these students had subsequent impaired academic performance in word recognition, spelling, and arithmetic.

To investigate the possible association between chronic otitis media and school learning problems, Bennett, Ruuska, and Sherman (1980) conducted a study of 53 learning disabled (LD) students and compared them to 56 control students without learning problems. Results revealed that $38 \%$ of the ID students and $16 \%$ of the control group failed the puretone audiometry, and $49 \%$ of the LD students and $21 \%$ of the control group failed the tympanometry. A history of recurring otitis media was obtained for $23 \%$ of the LD students and 98 of the control group. The LD students performed below expectation on achievement, perceptual, and language tests. The conclusion reached was that there is an association between chronic middle ear disease and school learning problems.

Teele, Klein, Rosner, and the Greater Boston Otitis Media Group (1984) administered standardized speech and language tests to a group of 3-year-olds. Subjects who had spent a greater amount of time with middle ear effusion had significantly lower scores on these tests than subjects who had never had middle ear disease.

As reported in Chalmers, Stewart, Silva, and Mulvena, (1989), the Dunedin Study conducted in New Zealand in 1987 
studied 1,037 subjects ages 3 through 9 years over several years to determine if children with persistent middle ear disease had language and academic problems. The subjects were evaluated every 2 years with puretone audiometry. tympanometry, otoscopic examination, and developmental and behavioral tests. In the longitudinal analysis, the students with persistent middle ear disease had poor speech articulation and language skills, poor reading ability, and poor classroom behavior still evident at the age of 9 years. This is the first longitudinal study reported on children with middle ear disease with effusion and it needs to be replicated (Chalmers et al., 1989, Chap. 8).

Ventry (1980) published a review of research evidence implicating hearing impairment as a cause of language and learning problems. His opinion was that there were numerous flaws in previous studies and that more research was needed. Problems Ventry found in previous studies were lack of control of variables not being studied such as age, gender, type of hearing loss, ethnic group, and socioeconomic status. Other flaws were found in the use of inappropriate tests, biased interpretation of data results, and a failure to identify methods of statistical analysis. He concluded that the relationship had been poorly documented. There is a need for more research using longitudinal design, comparison of similar groups, and correlational studies. In 
1982, Ventry maintained his opinion that a causal link between hearing impairment and language and learning problems had not been established (Bluestone et al., 1983, p. 644).

During a workshop held in Chicago (1982) to discuss otitis media and its effect, Gray reported that studying the effect of otitis media on academic progress creates a problem because the studies attempt to measure cognitive development, a broad area of higher mental processes, using tests dependent on receptive and expressive language. If an effect is found, will it be a delay in development or a permanent loss (Bluestone et al., 1983, p. 645)? MCWilliams discussed the relationship between hearing impairment and the development of language. There is no doubt that a relationship exists, but there may be multiple causes to consider (Bluestone et al., 1983, p. 646).

Cross (1985) wrote that profound hearing loss clearly affects language development and learning, but it is unclear what effect mild and fluctuating hearing loss, commonly found with middle ear disease with effusion, has on language and learning. Roberts et al. (1986) conducted a study on 61 subjects who had otitis media during the first 3 years of life and subsequent verbal and academic problems during the primary school years. Standardized intelligence and academic achievement tests were used. Results revealed no 
evidence of an association between middle ear disease early in life and verbal and academic problems during the early school years.

Following the 1982 Otitis Media Workshop, Gates declared that although results of studies showing an association between middle ear disease and language dovelopment and academic achievement are disputed, a student with otitis media may be distracted due to pain, hearing loss, listlessness, and irritability resulting from the middle ear disease. This distraction may interfere with concentration and the student's desire to excel. Some students regain lost academic progress when they feel better, but others do not (Bluestone et al., 1983, p. 648). Development of Puretone Audiometry and Iumpanometry

Puretone screening audiometry was introduced in the Minneapolis public schools in 1938. Since its introduction, various puretone frequencies and intensity levels have been used in the public school hearing test programs. As reported in McDermott (1982), the Pittsburgh Study done in 1967 by Eagles, Wishik, and Doerfler found that $61 \%$ of students who passed the puretone audiometry screening had evidence of abnormal middle ears upon otoscopic examination. A better method was needed to identify students who needed to be referred for medical evaluation. 
Acoustic immittance has evolved in Europe and the United states since the 1940 s as an objective test for detecting middle ear conditions (Stach, 1987). Metz described an electroacoustical method to detect changes in middle ear impedance and acoustic reflex in 1946. His purpose was to develop an objective method to evaluate middle ear function (Metz, 1946, p. 12). In the United States, Zwislocki and Feldman developed an electromechanical method to measure impedance. In Europe, Thomsen, Terkildsen, Moller, and others developed an impedance bridge based on electroacoustic principles, the prototype of the modern impedance audiometer (Jerger, 1970). In 1969, Brooks introduced impedance audiometry as a screening tool to identify middle ear disease (Brooks, 1969), and in 1978, Brooks recommended the use of impedance audiometry in school hearing screening programs (Renvall \& Lindén, 1980). Recommendations for Hearing Screening by Professional Groups

Various symposiums have been held during the last 20 years to discuss middle ear disease and to determine what hearing screening best detects it. Professional groups have made recommendations for tests that should be included in hearing screening programs. In 1977, a national symposium was held in Nashville, Tennessee to study acoustic immittance for children. The committee recommended that impedance screening not be used in mass hearing screening 
programs until more is known of its advantages and limitations. The committee issued guidelines for professional audiometrists already using impedance screening, including a second screening before referral for a medical evaluation (Bluestone, 1978). The American Speech-Language-Hearing Association published guidelines for acoustic immittance screening in 1979 (ASHA, 1979).

In 1984, a workshop was held in Washington, D.C. for the purpose of gathering health professionals to review information on hearing screening for otitis media in children. The group did not recommend using acoustic immittance in mass hearing screening until acoustic immittance screening is based on meaningful guidelines. The recommendation was made that a national task force be formed to disseminate information on otitis media that clearly defines the target population and to recommend guidelines for screening programs (Bluestone et al., 1986).

The American Academy of Pediatrics Committee on School Health (1987) recommended that acoustic immittance should not be used for mass screening for the detection of middle ear disease, but used only on children at high risk for otitis media or who are suspected of having otitis media. Puretone audiometry should be the primary method used in screening programs (American Academy of Pediatrics, 1987). 
The California State Department of Health Services requires a puretone screening at $25 \mathrm{~dB}$ for the frequencies of $1000 \mathrm{~Hz}, 2000 \mathrm{~Hz}$, and $4000 \mathrm{~Hz}$. If the student fails to hear any tone at 25dB, a puretone threshold test is immediately required. A threshold is established for the frequencies of $500 \mathrm{~Hz}, 1000 \mathrm{~Hz}, 2000 \mathrm{~Hz}$, and $4000 \mathrm{~Hz}$. If the student fails to hear at $30 \mathrm{~dB}$ or greater in two frequencies in either ear or at $40 \mathrm{~dB}$ or greater in one frequency in either ear, the student fails the test. A second puretone threshold is recommended in a minimum of 2 weeks before referral is made for a medical examination. Tympanometry is not recommended (DHS, 1989).

The National Association of School Nurses recommends a testing program using puretone audiometry and tympanometry. Students are screened with puretone audiometry initially. Students who fail the first puretone screening are given a second puretone screening in 2 weeks. For students who fail the second puretone screening, a puretone threshold test and tympanometry are recommended. The testing should be done in a quiet room. An otoscopic examination is recormended before the tympanometry screening to determine the condition of the external ear canal and tympanic membrane. Fail criteria for the puretone screening is failure to hear one or more tones in either ear at $25 \mathrm{~dB}$ for the frequencies of $1000 \mathrm{~Hz}, 2000 \mathrm{~Hz}$, and $4000 \mathrm{~Hz}$. Thresholds are established 
at $1000 \mathrm{~Hz}, 2000 \mathrm{~Hz}, 3000 \mathrm{~Hz}$, and $4000 \mathrm{~Hz}$ and a tympanometry screening is administered. Each state's Department of Education establishes its own criteria for failure thresholds (NASN, 1993).

The American Speech-Language-Hearing Association (ASHA, 1985) recommends a testing program for puretone screening at $20 \mathrm{~dB}$ for the frequencies of $1000 \mathrm{~Hz}, 2000 \mathrm{~Hz}$, and $4000 \mathrm{~Hz}$. If tympanometry is not done, $500 \mathrm{~Hz}$ should be included. Fail criteria is failure to respond at $20 \mathrm{~dB}$ at one or more frequencies in either ear. Students who fail the screening are given a second puretone screening test preferably within the same testing session and then given an otoscopic examination and a tympanometry test. Suggested criteria for a normal tympanogram for children are (a) peak compliance between 0.2 and $0.9 \mathrm{ml}$, (b) ear canal volume between 0.4 and $1.0 \mathrm{ml}$, (c) tympanometric width between +60 and $-150 \mathrm{~mm}$ water. A second test in 4 to 6 weeks is recommended before referral is made. Tympanometry failure is a flat tympanogram or equivalent canal volume outside the normal range, low static immittance, and tympanometric width outside normal range on two successive occurrences at 4 to 6 week intervals. Medical referral criteria should be based on case history, otoscopic inspection, puretone audiometry, and tympanometry to avoid the excessive overreferral rates which occur when tympanometry results are used alone (ASHA, 1990). 
Studies Emploving Puretone Audiometry and Tympanometry

in the School setting

Puretone audiometry is effective in identifying sensorineural hearing loss but less effective in identifying middle ear disease. Several studies have been done on school age children over the past 20 years to evaluate the use of puretone audiometry to identify hearing loss and middle ear disease.

In 1975, Beery, Bluestone, and Cantekin conducted a study in the parochial schools of Boston on 771 five to seven-year-olds between October, 1973 and April, 1975. The purpose of the study was to develop a hearing testing protocol using patient history, puretone audiometry, and tympanometry.

Using puretone audiometry administered at $25 \mathrm{~dB}$ in frequencies of $500 \mathrm{~Hz}$ through $8000 \mathrm{~Hz}$, students were screened to determine if they failed to respond to two or more frequencies at 25dB. Tympanometry was administered with a failure criteria of middle ear pressure below -150 mm water. Testing was repeated in 4 to 6 weeks for those subjects who failed the first tests.

Results revealed that $57 \%$ of the subjects passed both puretone audiometry and the tympanometry, 298 of subjects were at risk for developing middle ear disease based on a history of middle ear disease, and 148 of subjects were 
referred. No results of medical examinations were reported. The recommendation made was that students be given a second test before referral to avoid referring students whose middle ear effusion would resolve spontaneously.

Renvall and Holmquist (1976) conducted a study in Sweden using puretone audiometry and tympanometry to evaluate the effectiveness of tympanometry to identify school children with secretory otitis media. Sixteen hundred ears of 7-year-olds were randomly selected. Using puretone audiometry at $250 \mathrm{~Hz}$ through $8000 \mathrm{~Hz}$, students were screened to determine if they failed to respond to two or more frequencies at $20 \mathrm{~dB}$. Tympanometry was administered to each student with failure criteria of middle ear pressure below $-100 \mathrm{~mm}$ water or a flat tympanogram.

Results reported from the above study were that $6.5 \%$ of subjects failed the puretone screening and $13.5 \%$ failed the tympanometry. Students failing the tympanometry were given a second test in 6 to 12 months. At that time $20 \%$ of subjects failed the puretone screening, $40 \%$ of subjects failed the tympanometry, and $14 \%$ of the subjects were diagnosed with middle ear effusion. Renvall and Holmquist (1976) concluded that referral was required when middle ear pressure below $-150 \mathrm{~mm}$ water was found on tympanometry, since middle ear pressure below $-150 \mathrm{~mm}$ water can be predisposing to secretory otitis media. Middle ear effusion 
increased between testing, indicated by a tympanometry failure rate of $13.5 \%$ at the first testing and a $40 \%$ failure rate at the second testing.

In 1980, Renvall and Lindén reported four studies on 11,722 seven-year-olds using puretone audiometry and tympanometry between 1972 and 1978 in Swedish schools. The goal of the study was to find an ideal screening level to accurately identify subjects who had middle ear disease diagnosed by the otologist.

A puretone screening at $20 \mathrm{~dB}$ in frequencies of $500 \mathrm{~Hz}$ and $3000 \mathrm{~Hz}$ was administered to each subject, with a failure criteria of hearing above $20 \mathrm{~dB}$ at two or more frequencies. Tympanometry was administered to each subject, with a failure criteria changing from below $-80 \mathrm{~mm}$ water in the first study to below $-150 \mathrm{~mm}$ water in the last study to establish an effective level of negative pressure to identify middle ear disease. A repeat testing was administered 4 weeks following failure of the first tests to eliminate subjects with occasional episodes of negative middle ear pressure.

Results from the fourth study revealed that $2.5 \%$ of the subjects failed the puretone screening, $6.3 \%$ of the subjects failed the tympanometry, and $5.8 \%$ of subjects were diagnosed with middle ear disease by otoscopic examination. Renvall and Lindén recommended the use of puretone screening at $20 \mathrm{~dB}$ 
in two frequencies, $500 \mathrm{~Hz}$ and $4000 \mathrm{~Hz}$, supplemented by tympanometry, with failure criteria of middle ear pressure below $-150 \mathrm{~mm}$ water or a flat tympanogram. They also recommended a repeat tympanometry screening failure before referral for a medical evaluation (Renvall \& Lindén, 1980). Following the promising results of the Renvall and Lindén study, Gimsing and Bergholtz (1983) decided to use tympanometry in the routine screening of school children and conducted a study of 532 seven-year-olds and 588 ten-yearolds during October and November of 1981 in Swedish schools. The purpose of the study was to ascertain if tympanometry as proposed by Renvall and Lindén (1980) identified a significant number of students with middle ear disease.

A puretone screening was administered at $20 \mathrm{~dB}$ in frequencies of $500 \mathrm{~Hz}, 1000 \mathrm{~Hz}$, and $2000 \mathrm{~Hz}$ to each student with a failure criteria of not hearing above $20 \mathrm{~dB}$ at two or more frequencies. Tympanometry was administered to each student with a failure criteria of middle ear pressure below $-150 \mathrm{~mm}$ water or a flat tympanogram. Students who failed the first tests were given second tests in 4 to 8 weeks. Results of the study revealed that $30 \%$ of the 7-year-olds and 17\% of the 10-year-olds failed the school screening tests. Seven percent of the 7-year-olds and $6.6 \%$ of the 10-year-olds failed only the puretone, and $16 \%$ of the 7-year-olds and 8\% of the 10-year-olds failed only the 
tympanometry. Middle ear disease was diagnosed throughout the study in 2 to $5 \%$ of the 7-year-olds and 0.5 to $1.0 \%$ of the 10-year-olds.

Results confirm that puretone audiometry alone can not reliably detect middle ear effusion since the hearing loss in these conditions can not always be detected at the $20 \mathrm{~dB}$ level. The high sensitivity of tympanometry may result in unnecessary referrals since serous otitis media may resolve spontaneously. Gimsing and Bergholtz (1983) recommended (a) that justification for mass screening of 7-year-olds is questionable due to the middle ear prevalence rate of 2-3\% at this age; (b) that if tympanometry is done, the criteria for tympanometry failure be set at a middle ear pressure of $-250 \mathrm{~mm}$ water; and (c) that testing should be done at first grade, when middle ear disease is more prevalent, and once again before the students graduate from high school to detect hearing loss that could influence choice of occupation, rather than at various grades throughout the school years.

FitzZaland and zink (1984) reported a study in Canada of 3,510 kindergarten and first grade students, 4 through 7 years of age. In the school hearing conservation program, there had been a 40-90\% rate of false positive results. The purpose of the study was to evaluate the effectiveness of puretone audiometry and investigate alternative screening 
methods. Following tester training, control of instrument calibration, and ambient noise control, the rate dropped to $20-308$.

Puretone audiometry was administered at $20 \mathrm{~dB}$ for $1000 \mathrm{~Hz}$ and $2000 \mathrm{~Hz}$ and at $25 \mathrm{~dB}$ for $500 \mathrm{~Hz}$ and $4000 \mathrm{~Hz}$. Fail criteria was failure to respond at these decibel levels at one or more frequencies in either ear. Tympanometry was administered with a failure criteria of below $-200 \mathrm{~mm}$ water or a flat tympanogram. If the student failed either test, a second test was given. Results revealed that 3,373 (96\%) of the students had normal hearing results and normal middle ear function. Of the 167 students who failed the puretone audiometry, 128 had an abnormal and 39 had a normal otological examination. Of the 198 students who failed the tympanometry, 125 had an abnormal and 73 had a normal otological examination. Fitzzaland and zink (1984) concluded that puretone audiometry missed the fewest students with confirmed hearing impairment and that the high false positive rate of tympanometry would overburden the hearing conservation program, although the combination of puretone audiometry and tympanometry missed no abnormal middle ears.

A study reported by Roush and Tait (1985) evaluated the screening criteria set by ASHA and the Nashville group. Seventy five 3 and 4-year-olds were studied using puretone 
audiometry and tympanometry. A second screening was done on students who failed the first screening according to the Nashville guidelines, but results were also projected using the ASHA criteria of referral after one screening.

Results revealed that $71 \%$ of subjects passed the first screening. Of the $29 \%$ of subjects who failed the first screening, one half passed the second screening. In general, the findings agree with the Nashville guidelines and support the need for rescreening before referral for medical evaluation. There was a higher false positive rate on referral made upon results of one screening. Referral based on the ASHA criterja projected a $56 \%$ overreferral rate, while the Nashville guidelines resulted in an overreferral rate of $27 \%$ (Roush \& Tait, 1985).

A study reported by West (1987) of 100 preschool children, ages 2.5 to 5.5 years of age, used both puretone and bone conduction audiometry and impedance audiometry. The purpose of the study was to reexamine the effectiveness of impedance audiometry as a screening method using the audiometric air-bone gap as a validation criterion.

Puretone screening at $25 \mathrm{~dB}$ in the frequencies of $500 \mathrm{~Hz}$ through $4000 \mathrm{~Hz}$ was administered with failure criteria of hearing above $25 \mathrm{~dB}$ in two or more frequencies. Tympanometry was administered on the same day, with failure criteria of middle ear pressure below $-150 \mathrm{~mm}$ water. After failing the 
above screening, the subjects were given a puretone threshold and bone conduction threshold hearing test. Puretone testing was done in a sound-treated booth. An air conduction threshold of $10 \mathrm{~dB}$ lower than a bone conduction threshold is indicative of abnormalities of the middle ear. Results from the study revealed a higher percentage of failure following the impedance screening than following the puretone threshold screening. In the puretone audiometry group, 26.5\% of subjects failed the puretone screening, while in the impedance group $52.2 \%$ of subjects failed. The conclusion is that impedance audiometry is effective in a hearing screening program using the audiometric air-bone gap as a validation criteria (West, 1987).

Bonny (1989) reported a 5 year study on 2,409 children entering state schools in Great Britain. The purpose of the study was to determine if the use of puretone audiometry and tympanometry would detect more children with unresolved serous otitis media, thereby easing the load from overreferrals on the community audiology clinic.

Using puretone audiometry at frequencies of $500 \mathrm{~Hz}$, $1000 \mathrm{~Hz}, 2000 \mathrm{~Hz}$, and $4000 \mathrm{~Hz}$, students were screened to determine if they failed to respond to two or more frequencies at $25 \mathrm{~dB}$. Tympanometry was administered to each student with failure criteria of middle ear pressure below $-200 \mathrm{~mm}$ water or below $0.2 \mathrm{ml}$ of peak compliance. Students 
who failed the first screening were given a second test in 6 weeks, and students who failed the second screening were referred to the community audiology clinic. Of the 2,409 subjects, 1,167 subjects failed the first tests, 407 failed the second tests and were referred to the audiology clinic for additional testing and medical examination. Results of the ear medical examinations were not reported. Tympanometry took very little additional time, was more acceptable to children, and was preferred by nurses. Although the number of referrals to the audiology clinic was not remarkably greater, more information was available on which to base the referral decision. As a result of the study, Bonny (1989) recommended using puretone audiometry and tympanometry to screen children entering school.

Holtby and Forster (1992) conducted a study of 610 six-year-old school children between February and July, 1988, in England. The purpose of the study was to evaluate tympanometry results against puretone audiometry results to detect middle ear changes that resulted in hearing loss. Using puretone audiometry at frequencies of $250 \mathrm{~Hz}$ through $8000 \mathrm{~Hz}$, students were screened to determine if they failed to respond to two or more frequencies at $20 \mathrm{~dB}$. Tympanometry was administered to each student with a failure criteria of middle ear pressure below $-150 \mathrm{~mm}$ water, or a compliance curve of less than $0.2 \mathrm{ml}$. Students who failed 
either test were given a second screening in 6 weeks. Puretone audiometry screening was done by school nurses and tympanometry by doctors.

Results from the first screening revealed that 99 subjects $(17 \%)$ failed both the puretone audiometry and the tympanometry, 73 subjects (13\%) failed the puretone audiometry screening, and 92 subjects (16\%) failed the tympanometry. Results of the second screening revealed that 46 subjects failed both the puretone audiometry and tympanometry, 29 subjects failed the puretone audiometry, and 36 subjects failed tympanometry. Results revealed the benefits of two stage tympanometry testing included a higher sensitivity and predictive rate than puretone audiometry. A recommendation was made that a study to confirm results be done by school nurses.

\section{Summary}

Dysfunction of any part of the auditory system interrupts the transmission of sound waves to the brain and deprives the student of important sensory information. Conductive hearing loss is the most common type of loss, and otitis media with effusion is the most common cause of conductive hearing loss. The effect of hearing loss on language development and academic progress is disputed, but most educators agree that hearing loss has an effect on a student's academic progress. The NASN and ASHA recommend 
the use of tympanometry as part of the hearing screening protocol. In several studies using puretone audiometry and tympanometry, more students failed the tympanometry than the puretone audiometry, and a second screening using puretone audiometry and tympanometry was recommended before referral for medical evaluation. Puretone audiometry identifies hearing loss with or without middle ear disease, while tympanometry identifies students with middle ear disease, with or without a hearing loss. 


\begin{abstract}
Chapter 3
METHODOLOGY

Study Design

The purpose of this study was to compare the difference in the number of students identified with hearing loss and middle ear disease using puretone threshold audiometry and tympanometry, as compared to the number of students identified with hearing loss and middle ear disease using puretone threshold audiometry alone. A descriptive nonexperimental design was used for this study. A convenience sample was used for subject selection.

The Sample

Subjects were students between the ages of 6 and 12 years in grades $1,2,5$, and special day classes who had failed the mandated puretone threshold audiometry in at least one ear. The researcher telephoned the parents of each student who failed the puretone threshold audiometry and asked permission to allow their student to participate in the study. A consent form (see Appendix C) was mailed to the parents who gave verbal permission for their student to be in the study.

Students were from a public school district located in a suburb community of the San Francisco Bay Area in Northern California. The district served 10,500 students in 11
\end{abstract}


elementary schools and 3 middle schools. Subjects were selected from all 11 elementary schools.

Demographic data collected included age, gender, and grade level. Students with a known hearing loss or known middle ear disease were not included in the study.

Study Approval

The study protocol was submitted and received approval from the Human Subjects Institutional Review Board, San Jose State University, San Jose, California, prior to the study (See Appendix A). Approval from the Evergreen School District was also obtained prior to the study (See Appendix B) .

Instruments

Testing for the study was done using the following instruments :

1. A Beltone, model 110, puretone air conduction audiometer calibrated to ANSI 1969 standards, provided by the Santa Clara County Office of Education.

2. A Beltone, model 119, puretone air conduction audiometer calibrated to ANSI 1969 standards, July 1993.

3. A Maico, model 110, immittance audiometer calibrated in september 1993 according to manufacturer's standards.

4. A Welch Allyn 3.5 volt halogen otoscope. 
Testing Procedure

Students in grades $1,2,5$, and students enrolled in special day class were given a puretone audiometry screening. Screening was done at $20 \mathrm{~dB}$ for the frequencies of $1000 \mathrm{~Hz}, 2000 \mathrm{~Hz}$, and $4000 \mathrm{~Hz}$. Each ear was tested separately. The students raised their hands to indicate that they heard the tone. Students failed the screening if they failed to hear any tone at $20 \mathrm{~dB}$ in either ear.

students who failed the puretone audiometry screening were given puretone threshold audiometry on the same day. Thresholds were established at the frequencies of $500 \mathrm{~Hz}$, $1000 \mathrm{~Hz}, 2000 \mathrm{~Hz}$, and $4000 \mathrm{~Hz}$. At each frequency, the tone was presented beginning at an intensity of $40 \mathrm{~dB}$, then decreased in increments of $10 \mathrm{~dB}$ until the tone was no longer heard by the student. This procedure was repeated three times until the tone was heard $50 \%$ of the time at one intensity, the threshold.

Puretone threshold audiometry began at $1000 \mathrm{~Hz}$, followed by testing at $2000 \mathrm{~Hz}$ and $4000 \mathrm{~Hz}$ to establish the threshold at each frequency. The $1000 \mathrm{~Hz}$ frequency was then tested a second time to establish the reliability of the test. The test was considered reliable when the two thresholds did not vary more than 5dB. Testing for a threshold at $500 \mathrm{~Hz}$ was done last. Each ear was tested separately. The following fail criteria required by DHS for 
the puretone threshold audiometry was used: (a) two thresholds of $30 \mathrm{~dB}$ in two frequencies in either ear or (b) one threshold of $40 \mathrm{~dB}$ or greater in a single frequency in either ear.

After parents gave permission for their student to participate in the study, the student was given an otoscopic examination of the ear canal and the tympanic membrane to determine if the ear canal was obstructed and if the tympanic membrane was intact. When the ear canal was clear and the tympanic membrane was intact, tympanometry was done to test the mobility of the tympanic membrane in each ear.

A tympanometry test was administered to each student. A low pitched tone $(226 \mathrm{~Hz})$ was presented into each ear canal, while air pressure was varied from +200 to $-400 \mathrm{~mm}$ water. Results were recorded on a tympanogram. A passing tympanogram had a peak pressure point between +100 and -190 $\mathrm{mm}$ water and a compliance peak of tympanic membrane mobility between 0.3 and $1.0 \mathrm{ml}$. An accepted failure criteria has not been established. The researcher chose the above specified criteria because it is recommended in the course required for certification of school audiometrists in the state of California.

The researcher tested all students in the study a second time using puretone threshold audiometry and tympanometry 2 to 4 weeks following the first testing. 
Students who failed the second puretone threshold audiometry or tympanometry were referred to their physicians for a medical ear examination.

The referral process included the following procedure: the researcher telephoned the parents of students who needed to be referred to a physician and then mailed a copy of the student hearing referral form to the parents, with the Physician's Report of Ear Examination at the bottom half of the form (See Appendix E). Physicians returned the Report of Ear Examination to the researcher.

The first puretone screening and threshold audiometry were done in the Santa Clara County office of Education Mobile Unit by the Santa Clara Office of Education Audiometrist, as contracted by the school district. The second puretone threshold audiometry and all tympanometry were done on the school sites by the researcher, a certified California school audiometrist and credentialed California school nurse.

\section{Data Collection}

Data collected from hearing test results and from physicians' reports were organized for a computer data file (See Appendix G). Confidentiality was maintained by a coding system (See Appendix F) that identified each student by number as well as by name, school, grade, and teacher. The coding system was kept at the researcher's home and was 
accessible only to the researcher. Audiometric test results (See Appendix D) and physicians' reports were filed in the student's health record folder at their respective schools, without identifying them as subjects of the study. The coding key was destroyed at the completion of the study. Students' screening results were organized into four categories. Ears in category 1 passed the puretone threshold audiometry and passed tympanometry; ears in category 2 failed the puretone threshold audiometry and passed tympanometry; ears in category 3 passed the puretone threshold audiometry and failed tympanometry; ears in category 4 failed the puretone threshold audiometry and failed tympanometry.

\section{Analytical Procedures}

Computerized statistical analysis was performed on the data using the sPSS, Statistical Package for the Social Sciences. Student demographic characteristics of gender, age, and grade level for the population were reported by frequency and percentage. The data were analyzed for the frequency and percentage of ears and students that were identified with hearing loss and middle ear disease by testing with puretone threshold audiometry and tympanometry compared to the frequency and percentage of ears and students identified with hearing loss and middle ear disease by testing with puretone threshold audiometry alone. 
The researcher chose to analyze data collected on ears instead of students since each ear has a separate test result and separate outcome classification. Although the two ears are part of the same body system, for the purpose of studying hearing testing methods, data collected on hearing test results and outcome classifications were analyzed by ears. 


\section{Chapter 4 \\ FINDINGS AND INTERPRETATIONS}

The purpose of this study was to compare the difference between the number of students identified with hearing loss and middle ear disease using puretone threshold audiometry and tympanometry and the number of students identified with hearing loss and midale ear disease using puretone threshold audiometry alone. This chapter describes the student demographic characteristics by gender, age, and grade level; reports findings of the data collected by number of ears; and describes procedures used to analyze the data. Findings are presented using tables and discussion.

Demographic Characteristics of the Sample Forty one students from 11 elementary schools participated in this study. Gender distribution was nearly equal. Twenty (49\%) of the students were male and 21 (51\%) were female. Students ranged in age from 6 to 11 years old. The majority of students, 28 (68\%), were 6 or 7 years old. Nineteen (46\%) 6-year-olds, 9 (22\%) 7-year-olds, 2 (5\%) 8-year-olds, 3 (7\%) 9-year-olds, 6 (15\%) 10-year-olds, and 2 (5\%) 11-year-olds participated. The majority of the students were first graders. Twenty one (51\%) first grade students, $10(24 \%)$ second grade students, 9 (22\%) fifth grade students, and one (2\%) student in a special day class participated in the study. The testing was done during the 
months of October and November, 1993. These months are the usual months for hearing testing in the school district. The reseacher avoided winter months when there is an increase in otitis media related to upper respiratory infections (Bluestone et al., 1986, p. 59). The medical ear examinations were done between october 1993 and February 1994 .

Results and Data Analysis

Results by Students: Analysis

Outcome classifications by gender showed that, of the 12 students classified with middle ear disease, 8 (67\%) were male and 4 (33\%) were female. Outcome classifications by age showed that, of the 12 students classified with middle ear disease, 7 (58\%) students were 6 years old, 3 (25\%) students were 7 years old, 1 (8\%) student was 8 years old, and $1(8 \%)$ student was 9 years old.

Results by Ears: Analysis

Hearing test results are reported by frequency and percentage. Although each student had two ears, each ear was reported separately since each ear had an individual test result and an individual outcome classification. Thus, for the 41 students in the study, there are results reported for 82 ears.

Results of the first and second puretone threshold audiometry and tympanometry tests are included. The results 
are divided into four categories. The four hearing test results categories are listed below.

1. Ears in category 1 passed puretone threshold audiometry and passed tympanometry.

2. Ears in category 2 failed puretone threshold audiometry and passed tympanometry.

3. Ears in category 3 passed puretone threshold audiometry and failed tympanometry.

4. Ears in category 4 failed puretone threshold audiometry and failed tympanometry.

The research testing protocol using puretone threshold audiometry, tympanometry, and otoscopic examination was the only testing protocol used in the study. To compare hearing test results obtained by the research protocol to the DHS protocol, the number of ears that failed only the puretone threshold audiometry was taken from hearing test results categories 2 and 4 .

A second test was administered within 2 to 4 weeks. Outcome classifications resulting from the referrals were reported by frequency and percentage and then arranged according to the hearing test results categories. The following paragraphs describe the results of both the first and second hearing tests and the outcome classifications resulting from medical ear examinations according to hearing test results categories. 
Table 1

Results of First Hearing Tests Reported by Ears According to Hearing Test Results Categories (Ear $\underline{\mathrm{N}}=82$ )

Category

1. Pass Threshold, Pass Tympanometry

2. Fail Threshold, Pass Tympanometry

3. Pass Threshold, Fail Tympanometry

4. Fail Threshold, Fail Tympanometry n

16

20

15

31
Percentage

$20 \%$

248

$18 \%$

$38 \%$

Table 2

Results of Second Hearing Tests Reported by Ears According to Hearing Test Results Categories (Ear $\underline{n}=76$ )*

\section{Category}

1. Pass Threshold, Pass Tympanometry

2. Fail Threshold, Pass Tympanometry 9

3. Pass Threshold, Fail Tympanometry 27

4. Fail Threshold, Fail Tympanometry
Percentage

$36 \%$

$12 \%$

$36 \%$

$17 \%$

* Note. Missing 6 ears that received medical evaluation prior to second testing. Percentages may not add to 100 due to rounding error. 
The results of the first hearing tests reported by ears according to hearing test results categories are presented in Table 1. Results of the second hearing tests reported by ears $(\underline{n}=76)$ according to hearing test results categories are presented in Table 2. Six ears did not receive a second hearing test as they received medical evaluation prior to the time the second testing was administered.

Referrals were based on the results of the second hearing test, using the research protocol with the exception of 6 ears. These 6 ears were either referred for medical evaluation upon failure of the first hearing tests when there was evidence of acute middle ear disease or were taken for medical evaluation by their parents/guardians before the second test was administered. The distribution of these 6 ears from the Table 1 categories was as follows: one ear was from category 1, one ear was from category 2, one ear was from category 3, and three ears were from category 4 .

Results of the medical ear examinations are reported using six outcome classifications. These classifications are normal findings (Normal), midale ear disease (MED), sensorineural hearing loss (SN), excess cerumen (EC), other findings (Other), and no referral (No Ref).

Results of ears referred from the second puretone threshold audiometry and tympanometry results, as well as the 6 ears medically evaluated after the first hearing test, 
are reported by hearing test results categories and outcome classifications in Table 3 . In the normal findings classification, 16 ears (20\%) were reported normal upon physical examination. In the ear pathologies classifications, 24 ears (29\%) were classified as having middle ear disease, 12 ears (15\%) were classified as having sensorineural hearing loss, and 11 ears (13\%) were classified as having excess cerumen in the external ear canal. Three ears (4\%) were included in the 'Other' findings classification. One ear had a foreign body in

Table 3

Ears Referred from Second Puretone Threshold Audiometry and Tympanometry Results According to Hearing Test Results Categories By Outcome Classifications (Ear $\mathrm{N}=82$ )*

\begin{tabular}{lccccccc}
\hline Category & $(\underline{n})$ & Normal & MED & SN & EC & Other & No Ref \\
\hline 1 & 28 & 8 & 2 & - & 2 & - & 16 \\
2 & 10 & - & 1 & 7 & 1 & 1 & - \\
3 & 28 & 6 & 13 & 1 & 7 & 1 & - \\
4 & 16 & 2 & 8 & 4 & 1 & 1 & - \\
Total & 82 & 16 & 24 & 12 & 11 & 3 & 16 \\
\end{tabular}

* Note. Includes 6 ears that received medical evaluation after the first hearing tests. 
the ear canal, and two ears were diagnosed as having external otitis media, inflammation of the external ear canal. Sixteen ears (20\%) were not referred for medical evaluation. Ears with a passing puretone threshold audiogram and tympanogram were considered normal and were not referred unless the other ear failed.

Results Related to the Research Question

Data from the sample were analyzed by frequency and percentage to answer the research question: "Does puretone threshold audiometry and tympanometry identify more students with hearing loss and middle ear disease than puretone threshold audiometry alone?"

Based on the second hearing test results and including the six ears evaluated on the basis of the first hearing test results for a total of 82 ears, ears identified by the research protocol referral criteria, "failure to pass puretone threshold audiometry and/or tympanometry," found in categories 2,3 , and 4 , totaled $54(66 \%)$ ears. Of these 54 ears, $24(44 \%)$ ears in categories 2 and 4 failed the puretone threshold audiometry and were identified as having a hearing loss. This hearing loss includes any type of hearing loss and is not limited to sensorineural hearing loss. In categories 2,3 , and 4 , twenty-two (418) ears were identified as having middle ear disease and eight (15\%) were identified as normal (see Table 3, p. 57). 
The results of the first and second hearing tests as reported in Tables 1 and 2 and the outcome classifications as reported in Table 3 are reported for each student in Table 4. Outcome classifications reported for each student are based on the ear with the "more serious results" when results differ. "More serious results" range from most serious to least serious as follows: middle ear disease, sensorineural hearing loss, excess cerumen, other, and normal.

Table 4 Students' First and Second Hearing Test Results By Category and Outcome Classification (Student $\mathrm{N}=41$ )

\begin{tabular}{lllll}
\hline & \multicolumn{2}{l}{$\begin{array}{l}\text { First Hearing Test } \\
\text { Category }\end{array}$} & \multicolumn{3}{l}{$\begin{array}{l}\text { Second Hearing Test Category } \\
\text { Outcome Classification }\end{array}$} \\
Student & Right Ear & Left Ear & Right Ear & Left Ear \\
1 & 2 & 1 & 1-No Ref & 1-No Ref \\
2 & 1 & 2 & $3-\mathrm{EC}$ & $2-\mathrm{EC}$ \\
3 & 1 & 2 & 1-No Ref & 1 -No Ref \\
4 & 1 & 2 & $3-\mathrm{Normal}$ & $3-\mathrm{SN}$ \\
5 & 3 & 4 & $3-\mathrm{EC}$ & $3-\mathrm{EC}$ \\
6 & 2 & 4 & $2-\mathrm{SN}$ & $2-\mathrm{SN}$ \\
7 & $4-\mathrm{EC}$ & $3-\mathrm{EC}$ & * & *
\end{tabular}

*Second Test Not Administered. 
Table 4 (Continued)

Students' First and Second Hearing Test Results By Category and Outcome Classification (Student $\mathrm{N}=41$ )

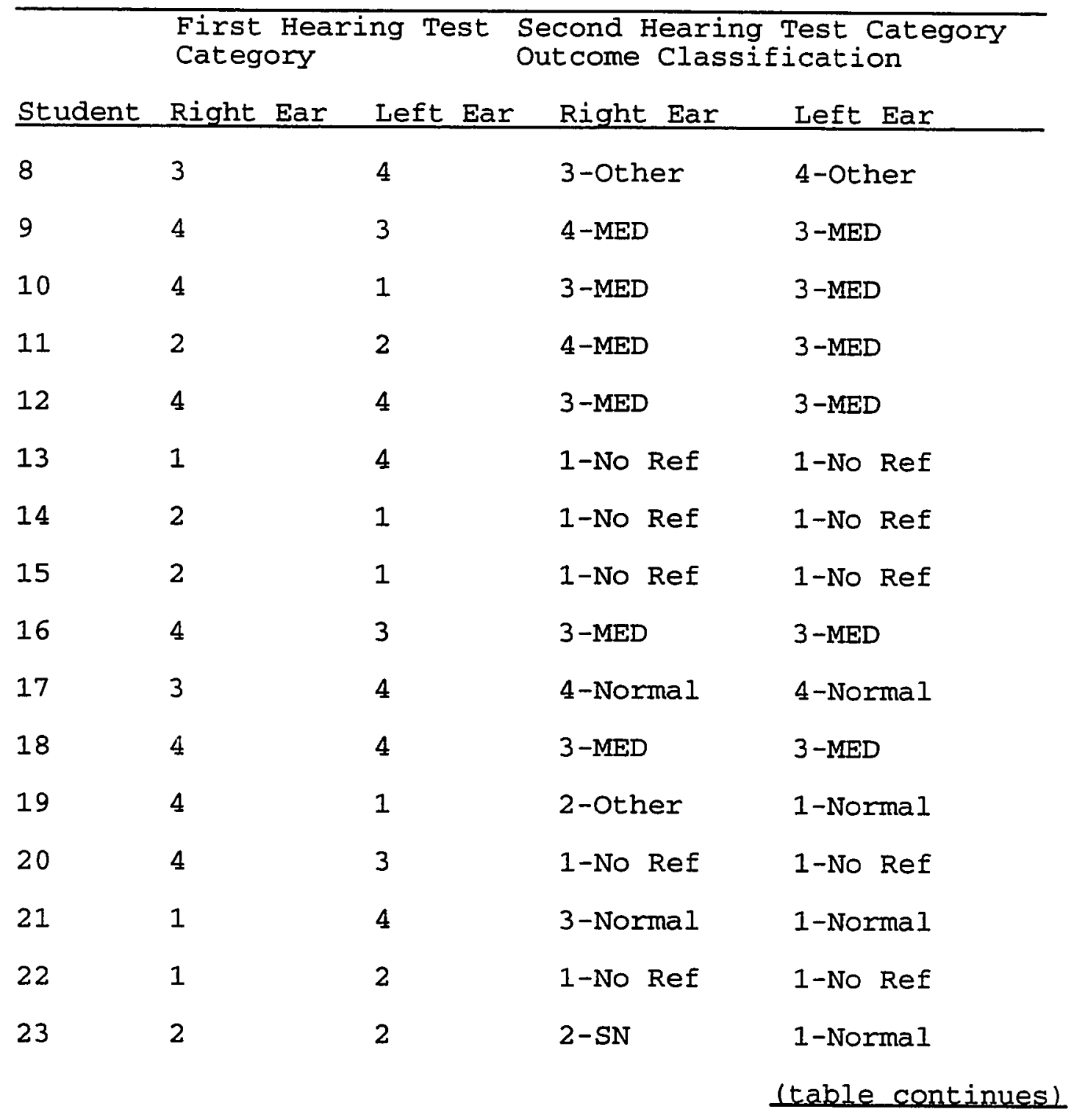


Table 4 (Continued)

Students' First and Second Hearing Test Results By

Category and Outcome Classification (Student $\mathrm{N}=41$ )

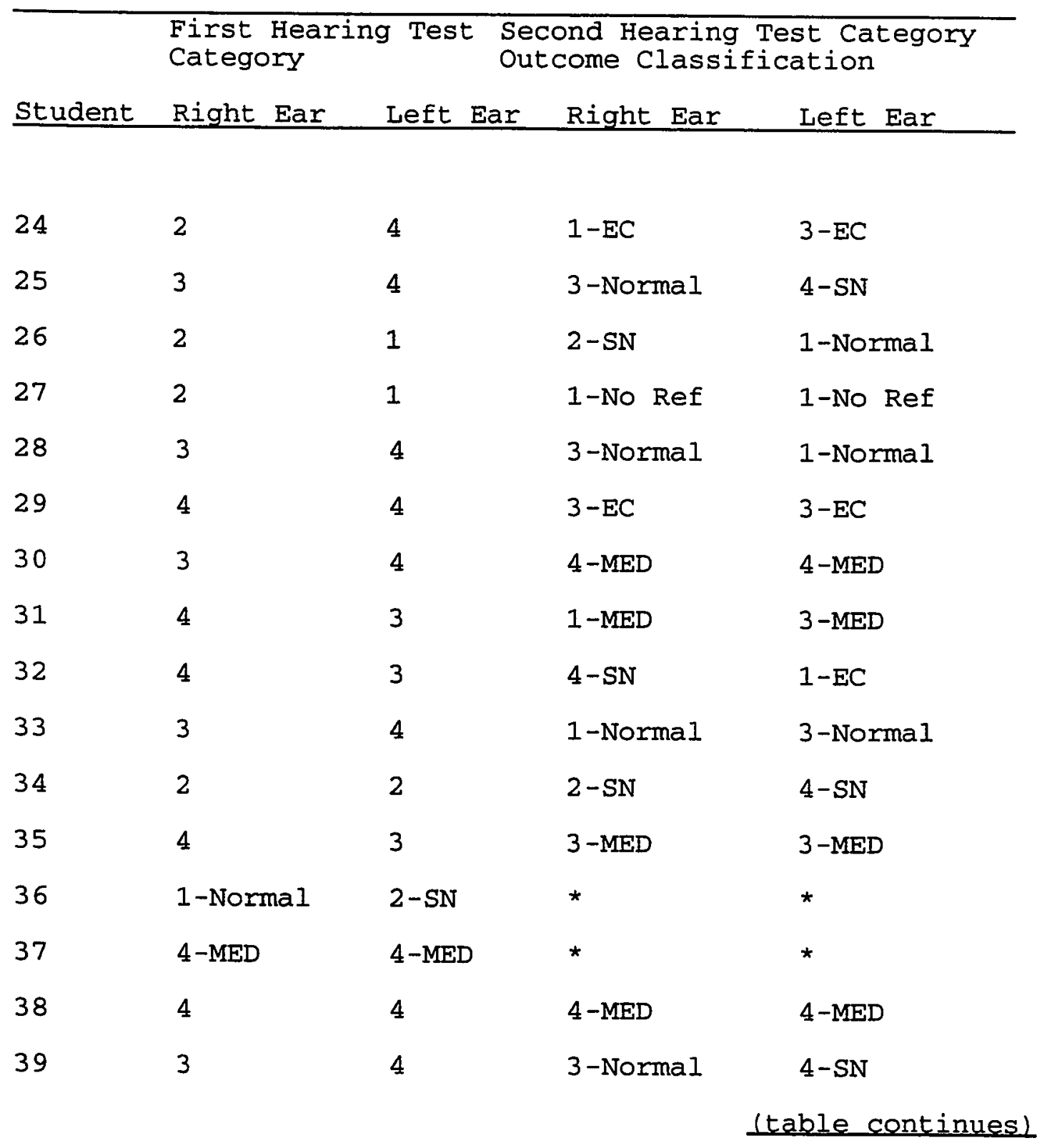

*Second Test Not Administered. 
Table 4 (Continued)

Students' First and Second Hearing Test Results By

Category and Outcome Classification (Student $\mathrm{N}=41$ )

\begin{tabular}{llllll}
\hline & \multicolumn{2}{l}{$\begin{array}{l}\text { First Hearing Test } \\
\text { Category }\end{array}$} & \multicolumn{3}{l}{$\begin{array}{l}\text { Second Hearing Test Category } \\
\text { Outcome Classification }\end{array}$} \\
Student & Right Ear & Left Ear & Right Ear & Left Ear \\
\hline 40 & 2 & 1 & $2-S N$ & $1-$ Normal \\
41 & 1 & 2 & $1-M E D$ & $2-M E D$ \\
\hline
\end{tabular}

Note. Test results categories: 1=Pass Threshold Pass

Tympanometry, 2=Fail Threshold Pass Tympanometry, 3=Pass

Threshold Fail Tympanometry, 4=Fail Threshold Fail

Tympanometry. Outcome Classifications: Normal=Normal

findings, $\mathrm{MED}=$ middle ear disease, $\mathrm{SN}=$ sensorineural hearing

loss, EC=excess cerumen, Other=other findings, No Ref=No

referral for medical examination.

The research question: "Does puretone threshold

audiometry and tympanometry identify more students by ears

with hearing loss and middle ear disease than puretone

threshold audiometry alone?", was answered. The same number

of students (by ears) were identified with hearing loss,

while more students (by ears) were identified with midale

ear disease using puretone threshold audiometry and

tympanometry. 
Summary

The purpose of this study was to compare the difference in the number of students identified with hearing loss and middle ear disease using the research protocol, puretone threshold audiometry and tympanometry, and the number of students identified using the DHS protocol, puretone threshold audiometry alone. The student demographic characteristics were presented in this chapter together with results by ears of the first and second hearing tests and results of second hearing tests by hearing test results categories and outcome classifications. The research question was answered: The same number of students (by ears) were identified with hearing loss, while more students (by ears) were identified with middle ear disease using puretone threshold audiometry and tympanometry. 


\section{Chapter 5 \\ DISCUSSION}

Summary of Study

Conductive and sensorineural hearing losses are common in the school age population. Hearing loss is believed to have a negative effect on language development and academic progress, therefore schools conduct hearing screening programs to detect hearing loss as required by the California Department of Health Services (DHS). Puretone threshold audiometry is the test currently required by DHS and is used in many of the school hearing programs. While puretone threshold audiometry is recognized as effective in identifying hearing loss, it is less effective in identifying middle ear disease.

Several studies support the use of a combination of puretone threshold audiometry and tympanometry to more effectively identify hearing loss and middle ear disease (Beery, Bluestone \& Cantekin, 1975; Bonny, 1989; Gimsing \& Bergholtz, 1983; Holtby \& Forster, 1992; Renvall \& Holmquist, 1976; Renvall \& Lindén, 1980; West, 1987). The purpose of this study was to determine if more students (by ears) are identified with hearing loss and middle ear disease by the researcher using puretone threshold audiometry and tympanometry or if more students (by ears) are identified using puretone threshold audiometry alone. 
The conceptual framework chosen for this study was Betty Neuman's systems model of nursing. The model provides a framework for nursing interventions and places emphasis on a holistic concept of wellness.

\section{Conclusions}

The final results of the study indicate that the use of puretone threshold audiometry and tympanometry identified the same number of ears with hearing loss as did the puretone threshold audiometry alone. The use of puretone threshold audiometry and tympanometry identified 22 ears with middle ear disease, which was more than puretone audiometry alone, which identified middle ear disease in 9 ears (See Table 3, p. 57). It is important to identify middle ear disease with a fluctuating hearing loss before it influences academic performance.

The two tests are complementary. Puretone threshold audiometry identifies sensorineural hearing loss and middle ear disease with conductive hearing loss, while tympanometry identifies middle ear disease with or without hearing loss. The major conclusion of this study is that the testing combination used in this study is a better protocol for identifying hearing loss and middle ear disease than the protocol required by the California Department of Health Services. A testing procedure that includes puretone threshold audiometry, tympanometry, and otoscopic 
examination, with a retest in 2 to 6 weeks, provides a superior protocol for a hearing screening program. Using the test combination of puretone audiometry and tympanometry identifies hearing loss due to treatable conditions, such as middle ear disease and excess cerumen blocking the ear canal. These conditions can be treated and hearing returned to normal before academic progress is affected. Hearing loss due to untreatable conditions can be identified early, thus modifications can be made in the classroom to enhance learning.

This study supports the recommendations made by the National Association of School Nurses (NASN, 1993) and the American Speech-Language-Hearing Association (ASHA, 1985) that puretone audiometry and tympanometry should be used together in school hearing screening programs. Because of the complementary nature of the tests, it is difficult to understand why the Department of Health Services does not require that tympanometry be included in the hearing screening protocol in California public schools. Several studies over the past 15 years have demonstrated the advantage of including tympanometry in hearing screening programs (Bonny, 1989; Holtby \& Forster, 1992; Renvall \& Lindén, 1980; Renvall \& Holmquist, 1976).

The student demographic characteristics in this study showed a greater number of boys and a greater number of 6 
and 7-year-olds with middle ear disease. This finding is consistent with the literature. Middle ear disease occurs more frequently in boy than girls. It is more common during the first 2 years of life, decreasing in incidence with the increase in age as evidenced in this study in younger boys. (Northern \& Downs, 1991, p. 65).

Previous studies have reported a difference in results between first and second hearing tests (Beery, Bluestone \& Cantekin, 1975; Holtby \& Forster, 1992; Renval1 \& Holmquist, 1976; Renvall \& Lindén, 1980; Roush \& Tait, 1985). In this study, $28 \%$ of the ears tested a second time passed the second hearing tests. The number of ears failing the first puretone threshold audiometry and passing the second puretone threshold audiometry increased by 29 ears in categories 2 and 4 (See Tables 1 and 2, p. 55). Had these ears been referred for medical evaluation, they would have been found to be normal, resulting in false positives, indicating a hearing problem when none exists. These changes in the numbers of ears passing puretone threshold tests may have occurred due to pathology that resolved spontaneously or because students were better prepared for the second test by receiving repeated instruction and by experience gained from the first test.

The number of ears failing tympanometry in category 3 increased from 15 ears at the first testing to 27 ears at 
the second testing (See Tables 1 and 2, p. 55). This increase may have been due to middle ear disease progressing and decreasing the mobility of the tympanic membrane.

These increases in numbers between the first and second hearing tests indicate that a second puretone threshold and tympanometry should be done to provide more accurate information on which to base referral for medical evaluation. This finding is consistent with the recommendations for hearing testing by the Department of Health Services, the National Association of School Nurses, and the American Speech-Language-Hearing Association.

The majority of ears (7) referred in category 2 were classified as sensorineural hearing loss (See Table 3 , p. 57). These students failed the puretone threshold audiometry which identifies hearing loss and passed tympanometry indicating the absence of middle ear disease.

Results showed that of the ears referred in category 3 , the greater number of ears (13) were classified as having middle ear disease (see Table 3, p. 57). These students passed the puretone threshold audiometry, indicating that a hearing loss did not exist with the middle ear disease at the time of the testing. Students in this category would not have been referred for medical evaluation using puretone audiometry alone, missing these ears with middle ear disease. 
In category 4, half of the ears referred (8) were classified as having middle ear disease (See Table 3, p. 57). These students failed the puretone audiometry and tympanometry, indicating the presence of conductive hearing loss with middle ear disease or sensorineural hearing loss with middle ear disease. One advantage of tympanometry for students with a permanent hearing loss is that failure of the tympanometry may indicate middle ear disease which would not be identified by using puretone audiometry alone.

Scope and Limitations

The convenience sample provided a small number of subjects for the study, limiting its external validity. Findings can only be specific for students in the school district and cannot be generalized.

The first puretone threshold testing was done by the Santa Clara County Office of Education audiometrist, while the researcher did all the other testing. Thus, two audiometrists did the hearing testing when one audiometrist would have provided more consistent results. Referrals were made to the students' private physician resulting in outcome classifications by many physicians. Referral to one physician would have provided more consistent results.

There were 6 ears classified by medical evaluation on the results of first test session, therefore they did not receive the second hearing tests. They were referred for 
medical evaluation upon failure of the first hearing tests when there was evidence of acute middle ear disease or because they had received medical evaluation before the second test session.

A soundproof room was not available for hearing testing at the school sites. The first hearing tests done by the Santa Clara County audiometrist were done in a soundproof van. The researcher did not use a sound level meter to test the noise level in the rooms used for testing at the school sites. A judgement of the maximum environmental noise level allowed for puretone audiometry was based on the experience of the researcher. It is difficult to find a quiet room in each school for hearing testing. Noise in the environment inhibits the ability to hear puretone air conducted sounds, especially at $500 \mathrm{~dB}$. Due to high student enrollment in the school district, the place of testing varies with the time of day. Student performance may become less reliable if the student experiences fatigue as the school day progresses. Tympanometry can be done regardless of the sound level in the room used for testing.

Ear examinations did not take place as soon as the students were referred. In some cases the problem causing the failure of the hearing test may have been resolved in the 1 to 3 months between referral and an ear examination. 
A standard of tympanometry fail criteria has not been established that is widely accepted by professionals. Audiometrists are using recommended standards that vary. For this study, the researcher selected the criteria for tympanometry failure recommended in the current course required for certification of school audiometrists in the state of California.

Recommendations for Future Research

1. A replication of this study with a larger sample is needed to validate results.

2. A replication of this study done by school nurses in school districts with school-based clinics where screening and medical examination by one practitioner can be done the same day is needed.

3. Studies are needed comparing both hearing loss and middle ear disease with student behavior, social skills, and speech and language skills.

4. Studies are needed to evaluate the effectiveness of adaptations in the classroom to meet the needs of students with hearing loss and/or middle ear disease.

5. Tympanometry studies are needed so norms can be established, thus providing tympanometry referral criteria for school age children. 


\section{Implications for School Nurse Practice \\ If school nurses agree that the purpose of the school} health services program is to maintain and improve the physical and mental health of students, it is the responsibility of school nurses to identify hearing problems before they have a negative impact on education. As advocates for children, school nurses must provide services to maintain the health of students and to assure maximum benefit from this important hearing sensory organ.

There are several areas of concern that must be addressed to improve the hearing testing program in the schools. School nurse preparation for administering hearing tests is important. School nurses must be prepared to administer puretone audiometry, tympanometry, and to perform otoscopic examinations on children of all ages. School nurses must: (a) be prepared for the process of referring students who have failed these tests, (b) know community resources, (c) help parents understand the problem, and (d) motivate the parents to act for the benefit of their children. School nurses must have a knowledge of the rehabilitation and adjustments needed in the educational program of students with a hearing loss.

In addition to identifying and referring students with hearing loss and middle ear disease, school nurses must assess the effectiveness of nursing interventions. More 
time is needed in the school nurses crowded work schedule for this important task.

At the primary level of prevention, health education is promoted to teach the students and parents a healthy lifestyle which will assist them to resist disease. Prevention of upper respiratory infections and avoidance of exposure to allergens is important for a healthy, normal functioning ear.

At the secondary level of prevention, the hearing testing program is conducted to identify symptomatology of the ear and hearing. Teachers must be informed of symptoms to alert them to refer students to the nurse for testing. Following the testing, when a hearing problem has been identified, a telephone call to the parent along with a written notice is more effective than a written notice alone. The advantage of a phone call is that the parent can ask questions and the nurse will know if the parent understands the implications of the test results, what action needs to be taken, and what resources are available to the parent. This direct communication is especially important when working with parents from numerous cultures who are not familiar with our medical system and who are comfortable using home remedies as their only resource. The nurse must be familiar with the cultural and religious practices of the parents with whom she works. 
Teachers must be made aware of the special needs of these students to help them reduce student stress and maintain student wellness. The student needs preferential seating, and may need to be reminded to go to the office for medication. Extra homework may have to be assigned and assistance provided to compensate for time lost for medical appointments. The student may need hearing aids, and the teacher must understand how to keep them working effectively and encourage the student to wear them to school. Hearing problems may threaten the child's self-esteem; encouragement and support from the teacher is essential.

At the tertiary level of prevention, rehabilitation is important, and an individual education plan may have to be developed. The strengths and weaknesses of the student need to be assessed and strengths developed. For the hearing impaired the visual sense must be strengthened. The school nurse must maintain an active position on the student study team and collaborate with school professionals, as well as with parents, for the benefit of the student. Hearing impairment must be considered when testing is done by the psychologist or speech therapist. Reports and recommendations from the doctor and audiologist must be used in writing an educational plan for the student. Students may need speech therapy from a speech and language specialist or counseling from a psychologist. 
A primary focus at this time must be to assess and approve a standard for hearing testing for California public schools based on research identifying students in need of medical treatment. School nurses and their professional organizations must advocate for updated DHS testing regulations. School district administrators must be educated and encouraged to provide a suitable test site for puretone threshold tests, according to ASHA recommendations (ASHA, 1990). As stated earlier, a quiet room is not necessary for tympanometry.

Classroom teachers, school nurses, physicians, and audiologists must work collaboratively in the community for the benefit of the hearing impaired student. All available resources in the community must be identified and made available to the students with hearing loss.

An effective testing protocol for identification of hearing disorders has been demonstrated to be a combination of puretone audiometry, tympanometry, and otoscopic examination. Puretone audiometry identifies a hearing loss, but it is limited due to the need for student understanding and cooperation to achieve accurate results. Obstacles to successful understanding and cooperation are age, ability to successfully complete the test, English speaking skills, fear, unwillingness to cooperate, and noise in the testing environment. 
Tympanometry identifies abnormal function of the middle ear. It is objective, and can be administered to all students regardless of age, ability, interest, or the test site. Tympanometry takes little additional time and money when compared to the value of additional findings. Tympanometry has a higher false postive rate than puretone audiometry; therefore, it should be used in conjunction with puretone audiometry and an otoscopic examination.

The otoscopic examination reveals the condition of the external canal and tympanic membrane, identifying students with acute otitis media who must be referred immediately. A history of middle ear disease or sensorineural hearing loss identifies a population in need of more regular testing than the general population.

Hearing testing using tympanometry is most effective with preschoolers, kindergarteners, and first grade students. These are the students most at risk for middle ear disease. Some of the preschool classes in the participating district are for language delayed students, and it is extremely important to identify, refer, and treat hearing disorders at this crucial time in the students' language development.

The researcher recommends that the puretone audiometry and tympanometry, along with the otoscopic examination, be included in hearing screening program in the lower 
elementary grades. This protocol provides more information on which to base a referral for medical evaluation.

The number of ears that passed the puretone audiometry and failed tympanometry but had middle ear disease or other disorders numbered 22 in this study (See Table 3, category 3, p. 57). Using puretone audiometry alone, these ears would not have been referred for medical evaluation. This number was reduced by using tympanometry which identified the majority of these students. The false positive ears that failed the tympanometry but had normal outcome classifications numbered 6 in this study. The number of false positives has been a factor against the use of tympanometry. The false positives of tympanometry can be reduced by using it with puretone threshold audiometry. Using the research protocol, the number of false positives and negatives for hearing loss and middle ear disease which has plagued the success of hearing screening programs can be reduced, making screening programs and the resulting referrals more effective.

School nurses must maintain and improve their testing and assessment skills with continuing education classes. Professional organizations such as the National Association of School Nurses and the California School Nurses Organization must take a leadership role in providing this 
education to help meet the needs of their school nurse members.

School nurses must actively advocate for DHS hearing regulation changes. Results of this study demonstrate that tympanometry and puretone threshold audiometry provide a hearing testing protocol that identifies more students with hearing loss and middle ear disease than puretone audiometry alone. The standards for testing must be brought up-todate. Professional school nursing organizations must play a leadership role in this area. 
REFERENCES 
References

American Academy of Pediatrics Committee on School Health (1987). Impedance bridge (tympanometer) as a screening device in schools. Pediatrics, 79, 472.

American Speech-Language-Hearing Association (1979).

Guidelines for acoustic immittance screening of middleear function. ASHA, 21, 550-558.

American Speech-Language-Hearing Association (1985).

Guidelines for identification audiometry. 소A, 27, 49-52.

American Speech-Language-Hearing Association (1990).

Guidelines for screening for hearing impairment and middle ear disorders. ASHA, 32 (Supp1. 2), pp. 17-24.

Ballantyne, D. (1990). Handbook of audiological technigues.

Great Britian: Butterworth-Heinmann.

Bennett, F., Ruuska, S., \& Sherman, R. (1980). Middle ear function in learning disabled children. Pediatrics, 66, 254-260.

Beery, Q. C., Bluestone, C. D., \& Cantekin, E. I. (1975). Otology history, audiometry and tympanometry as a case finding procedure for school screening. Larynoscope, 85, 1976-1985.

Bess, F.H. \& Humes, L.E. (1990). Audiology: The fundamentals. Baltimore: Williams-Wilkins. 
Bluestone, C., Klein, J., Paradise, J., Eichenwald, H., Bess, F., Downs, M., Green, M., Berko-Gleason, J., Ventry, I., Gray, S., McWilliams, B., \& Gates, G. (1983). Workshop on the effects of otitis media on the child. Pediatrics, 71, 639-651.

Bluestone, C.D. (1978). Use of acoustic impedance measurement in screening for middle ear disease in children. Pediatrics, 62, (4), 570-573.

Bluestone, C.D., Fria, T., Arjona, S., Casselbrant, M., Schwartz, D., Ruben, R., Gates, G., Downs, M., Northern, J., Jerger, J., Paradise, J., Bess, F., Kenworthy, O.T., \& Rogers, K. (1986). Controversies in screening for middle ear disease and hearing loss in children. Pediatrics, 77, 57-68.

Bonny, I. C. (1989). Five years experience of combined impedance and audiometric screening at school entry. Public Health, 103, 427-431.

Brooks, D. (1969). An objective method of detecting fluid in the middle ear. International Audioloov, 8, (568), $280-286$.

California Administrative Code of 1986, Title 17, Health Code, section 2951.

Chalmers, D., Stewart, I., Silva, P., \& Mulvena, A. (1989). otitis media with effusion in children-the Dunedin Study. Philadelphia: Lippincott. 
Cross, A. (1985). Health screening in schools. Journal of Pediatrics, 107, 487-494.

Department of Health Services: Maternal and Child Health Branch (1989). Manual for school audiometrist.

Sacramento, California: Author.

Fawcett, J. (1989). Analysis and Evaluation of Concentual Models of Nursing. Philadelphia: Davis.

Fiellau-Nikolajsen, M. (1983). Epidemiology of secretory otitis media. Annals of otology, Rhinology and Laryngoloay, 22, 172-177.

Fireman, P. (1987). Newer concepts in otitis media. Hospital Practice, $\underline{22}(11), 85-91$.

FitzZaland, R., \& Zink, G.D. (1984). A comparative study of hearing screening procedures. Ear and Hearing, 5, 205-227.

Giebink, G. S. (1988). Epidemiology of Otitis Media with Effusion. In F. H. Bess (Ed.) Hearing impairment in children (pp. 75-90). Parkton, Maryland: York. Gimsing, S., \& Bergholtz, L.M. (1983). Audiologic screening of seven and ten year old children. Scandanavian Audiology, 12, 171-177.

Holtby, I. \& Forster, D. P. (1992). Evaluation of puretone audiometry and impedance screening in infant schoolchildren. Journal of Enidemiology Community Health, 46(1), 21-25. 
Jerger, J. F. (1970). Clinical experience with impedance audiometry. Archive of Otolaryngology, 22, 311-324. Martin F. (Ed.) (1986). Hearing disorders in children. Austin, Texas: Pro-ed.

McDermott, J. (1982). Immittance screening for aural problems in school children. Journal of School Health, 52, 462-468.

Metz, O. (1946). The acoustic impedance measured on normal and pathological ears. Acta otolaryngologica. (Suppl. 63), 1-253.

Myers, D., Schlosser, D. \& Winchester, R. (1962). Otologic diagnosis and the treatment of deafness. Clinical Symposia, 14, (2), 42 .

National Association of School Nurses. (1993). Hearing screening quidelines for school nurses. Maine: Author. Neuman, B. (1995). The Neuman systems model (3rd ed). Norwalk, Connecticut: Appleton-Lange.

Northern, J. L. \& Downs, M. P. (1991). Hearing in children Baltimore: Williams-Watkins .

Paradise, J. L. \& Smith, C. G. (1979). Impedance screening for preschool children. Annals of otology, 88, 56-64. Renva11, U. \& Holmquist, J. (1976). Tympanometry-revealing middle ear pathology. Annals of otology, Rhinology and Iaryngology, 85 (suppl.25)，209-215. 
Renvall, U. \& Lindén, G. (1980). Screening procedure for detection of middle ear and cochlear disease. Annals of otology Rhinology and Laryngology, 89 (suppl.68), 214216.

Roberts, J., Sanyal, M., Burchinal, M., Collier, A., Ramsey, C., \& Henderson, F. (1986). Otitis media in early childhood and its relationship to later verbal and academic performance. Pediatrics, 78, 423-430.

Roush, J. \& Tait, C. (1985). Puretone and acoustic immittance screening of preschool aged children: an examination of referral criteria. Ear and Hearing, $\underline{6}$, 245-250.

Stach, B. A. (1987). The acoustic reflex in diagnostic audiology: From Metz to present. Ear Hearing, 8 (Suppl. 4) , 36S-4S.

Swanson, J.M. \& Albrecht, M. (1993) . Community health nursing-promoting the health of aggregates. Philadelphia: W. B. Saunders.

Teele, D., Klein, J., Rosner, B., \& The Greater Boston Otitis Media Group. (1984). Otitis media with effusion during the first 3 years of life and development of speech and language. Pediatrics, 74, 282-287.

Ventry, I. (1980). Effects of conductive hearing loss: Fact or fiction. Journal of Speech and Hearing Disorders, XLV, $143-156$. 
West, M. (1987). Evaluating impedance audiometry and audiometric air conduction. Unpublished master's thesis, San Jose State University, San Jose, CA.

Wilson, W. R. \& Walton, W. K. (1974). Identification audiometry accuracy: evaluation of a recommended program for school-age children. Language speech Hearing Services in Schools, 5, 132-142.

Zanga, J., \& Butts, F. (1991). Tympanometry in the schools: Is it worth the effort? Journal of School Health, I, $462-468$.

Zanga, Z. O., \& Oda, D. S. (1987). School health services. Journal of School Health, 57, 413-416.

Zinkus, P. W., Gottlieb, M. I., \& Schapiro, M. (1978) . Developmental and psychoeducational sequelae of chronic otitis media. American Journal of Diseases in Children, 132, $1100-1104$. 
Appendix A

Human Subjects Approval 
TO:

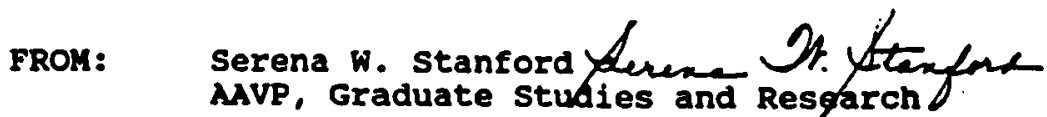

DATE: $\quad$ September 29, 1993

The Human Subjects-Institutional Review Board has approved your request to use human subjects in the study entitled:

\section{"The Use of Puretone Audiometry \& Tympanometry to Identity hearing Loss and Middle Ear Disease in School Age Children"}

This approval is contingent upon the subjects participating in your research project being appropriately protected from risk. This includes the protection of the anonymity of the subjects' identity when they participate in your research project, and with regard to any and all data that may be collected from the subjects. The Board's approval includes continued monitoring of your research by the Board to assure that the subjects are being adequately and properly protected from such risks. If at any time a subject becomes injured or complains of injury, you must notify Dr. Serena Stanford immediately. Injury includes but is not limited to bodily harm, psychological trauma and release of potentially damaging personal information.

Please also be advised that each subject needs to be fully inforwed and aware that their participation in your research project is voluntary, and that he or she may withdraw from the project at any time. Further, a subject's participation, refusal to participate or withdrawal will not affect any services the subject is receiving or will recelve at the institution in which the research is being conducted.

If you have any questions, please contact we at (408) 924-2480. 
Appendix B

District Approval 


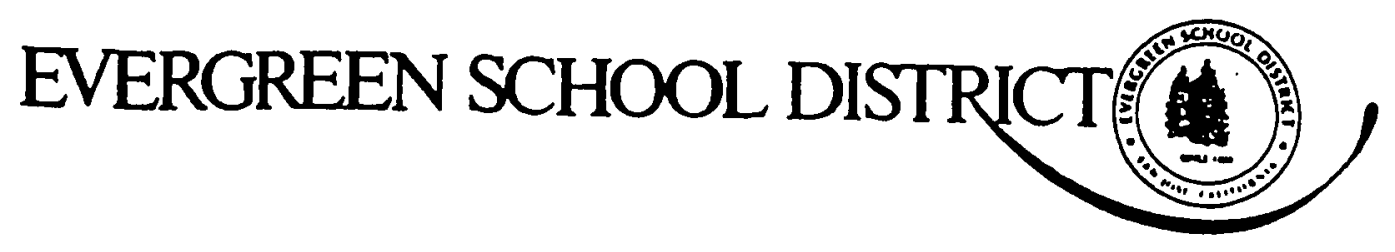

May 3, 1993

TO WHOM IT MAY CONCERN:

Mrs. Janet Mannina has been employed in Evergreen School District as a school nurse for several years. Her proposal to conduct a study with the acoustic impedance audiometry pure tone alr conduction audiometry and my full approval. Janet's no reason to belleve this project would be ben of a high callbre and I have to contact me should you have any would be any different. Please feel free

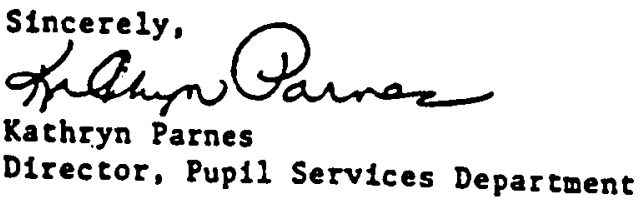


Appendix C

Agreement to Participate in Research 


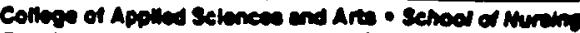

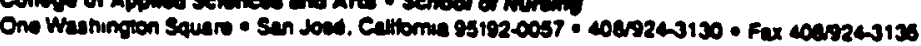

Agreement to Partleipate in Research

Respone1ble Inveetigator: Janet Mannina, B.S.A., R.R. School Muree and School Audlonetrlet

Istie of the study: The vee of Pure Tone Audsonetry and Typpanonetry to Identify Hearing Loes and Middie Ear Disere in School Age Chlidren

1. My chlld has been agked to perticlpate in a research etudy Invest lgating the effect lvenese of hearing teeting aethode that w1l accurately ldent 1 fy etudente with hearing loes and alddie
ear dieease.

2. I understand that ay chlid he falied the indtial hearing threshold teet. I underetand that in addition to the state mandated pure tone threshold alr conduction heering teet. I in glving peraiesion for ay chldd to have a typapanonetry tect perforwed and to have the neceseary preilninary otoscopic
exanination.

3. No riaks to my child are anticipated.

4. No diecernible beneflto to $\mathrm{nY}$ child are expected, other than poselbly a nore accurate ldentification of a hearing problea or on pathology.

5. The results of the etudy nen be publiohed, but no infornation that could Identify ay child w111 be included.

6. No compeneation for participetion in the etudy w111 be glven.

7. Any guestione about the reeeareh way be addreesed to Janet Mannina at (408) 39s-3778. Conplainte about the research nay be presented to Dr. Ginny Young. Aseoclate Profeseor, school of Kureing, theele advieor, telephone (408) 924-3163. For quevtlone or conpleinte about research, subjecte' righte or in the ovent of research-related injury, contact serens stanford, Ph.D.. Aleoclate Vice President of oraduate studies and Research, at (408) 924-2480.

8. No aervice of any kind, to which ay child is othorwiee entltind. will be loot of jeopardized 18 I refuee to have ay child "not participate" in the etudy. 
9. My consent is beling given voluntarily. I may refuse to have ny child participate in the study or in any part of the otudy. If ny child decides to participate in the study, he or she 18 free to withdraw at any time without prejudice to ay chlld'g or my relations with San Jose state Unlverslty, to ay chlld's school or the Evergreen School Diotrict.

10. I have recelved a dated copy of the consent form signed by the researcher-school nurse.

The signature of a parent or guardian on this document indicated approval for the child or ward to particlpate in the study and a statement that the child or ward is freely willing to participate.

Name of Ch1ld or Ward

Grade

Teacher

School

(Parent signature)

Researcher will type in parent name

Date

Full Malling Address

Janet MannIna, School Nurse

Date 
Appendix D

Puretone Threshold Audiogram and Tympanogram Form 
Data Collection Form $A$

Puretone Threshold Audiogram rorm

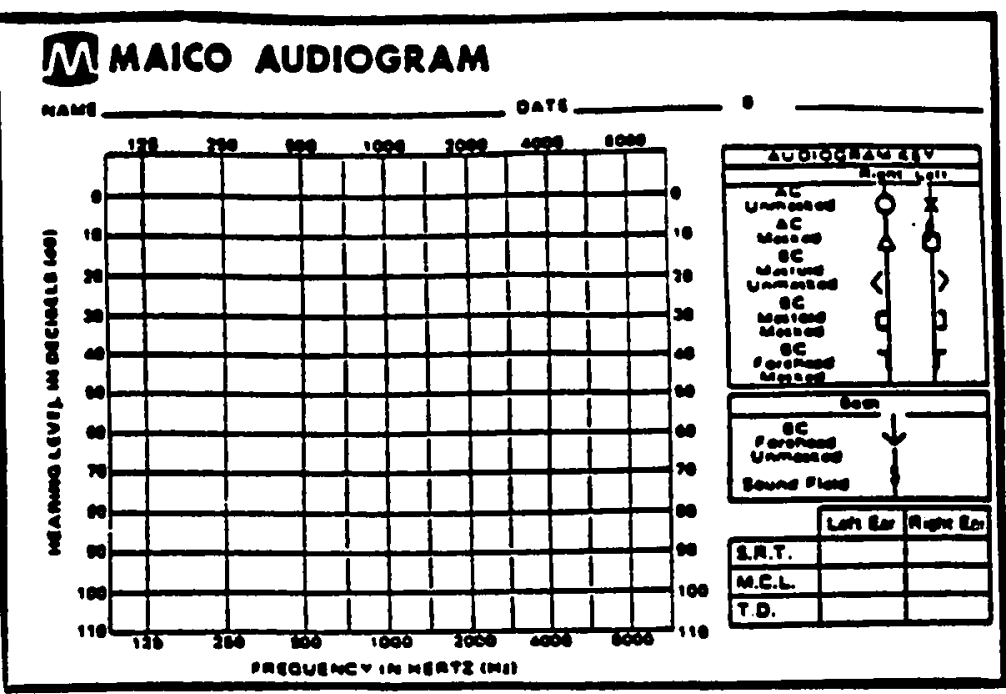

Tympanogram

NAME.

CATE.

CHTE............. EAR......

WUE...... TESTED BY.......

FK. COMPL. $0.6 \mathrm{ml}$

FK. PRESS. - 9 JAF:

PGRLAL VOL. $0.9 \mathrm{ml}$

REFLEX:

FRESENT IOS AE SPL

1.5:-

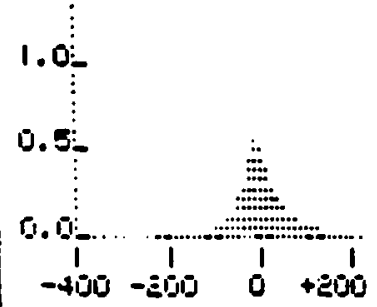

MADigo Minsto 
Appendix E

Physician Referral Form 
Data collection Form B

EVERGREEN SCHOOL DISTRICT

School Address

Date

Dear Parents:

Name of Pup11

was given a hearing test at school.

The results of this test Indicate that your child should be seen by your physictan for an orological (ear, nose and throat) examination. In order for the school to make the best plans for your child's school progran, this examination is important.

Today many children with hearlng losses, if treated early, way have the loss corrected before it becomes serious. Although some chlldren may have a temporary hearing loss during colds or other infections, It is important that the cause of such temporary loss be determined and treated to protect the child's future hearing. Please take the atcached wedical report forw and the report of your child's hearing test to your physictan.

The school will appreciate a report with your physiclan's recomendations.

D-131 (Revised 9/85)

School Nurse

Phone

Report of Physician to the School

Dear Doctor:

For your Information we have attached a copy of the most recent audiogram of

Name of Pup1l

Report of Examination

Diagnosis:

Prognosis:

Stationary

Will Improve

Progressive

Intermitrant

Comments and Recommendations:

Please complete and return form to:

Date of Examination

Examiner

D-131 (Rev. 9/85)

Addrese: 
Appendix F

Data Collection Form C 
Data Collection Eorm C

Subject Number

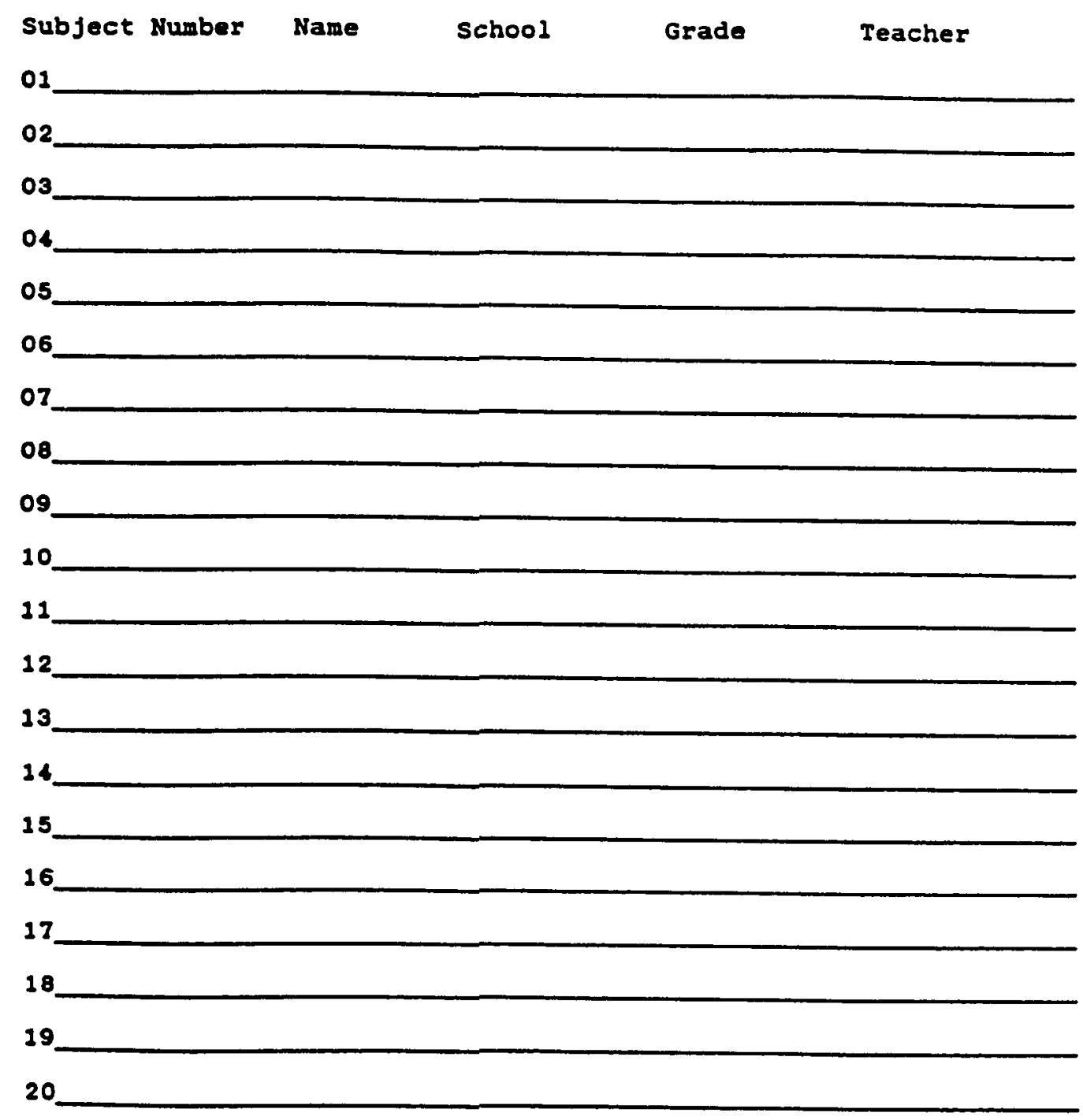


Appendix G

Data Collection Form D 


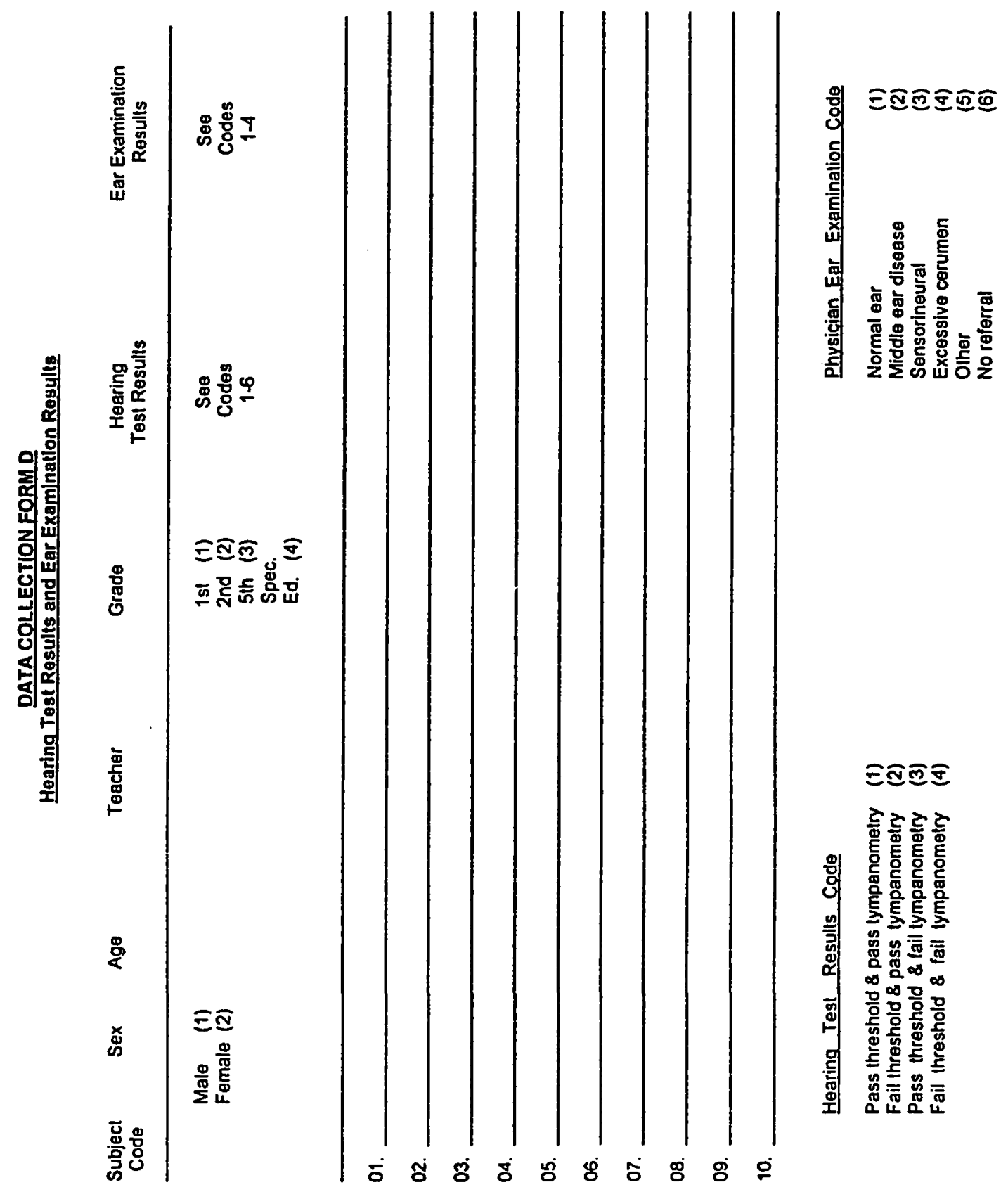


Janet Mannina, R.N.

16331 Cowell Road

Los Gatos, CAlifornia

Dear Mrs. Mannina,

You are hereby granted permission to use the 17 figure of the Neuman Systems Model found on page 26 of my publication, "The Neuman Systems Model" (2nd-Ed.). 1989, in your thesis. 1995

I am aware that this thesis will be submitted to University Microfilms, Inc. (UMI) for microfilm copy and that UMI will provide single copies upon demand.

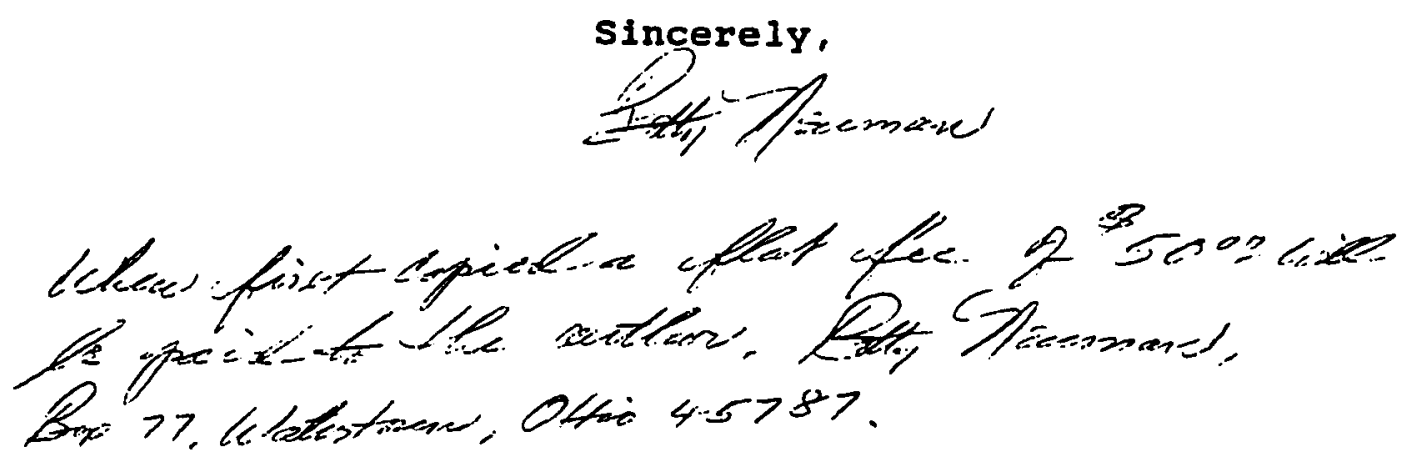


Janet Mannina, R.N. Graduate Nursing Student, SJSU 16331 Cowell Road

Ios Gatos, CA 95032

Dear Ms. Mannina:

Please accept my apology for the delay in responding to your request to use one plate from CIINICAI SMMOSIA, Volume 14, No. 1 in your thesis, "The Ose of Puretone Audiometry and Tympanometry to Identify Hearing Loss and Middle Ear Disease in School Age Children."

You are hereby granted permission to include Plate Number 1, from page number 42 of the Clinical symposia above in this one-time project for your Masters degree requirement.

Please note information below for artist's signature.

Thank you for your interest in Frank H. Netter's illustrations, and good luck on your thesis.

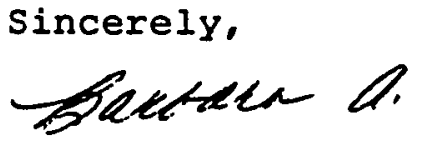

Barbara A. Burger Permissions Editor

$/ \mathrm{bb}$

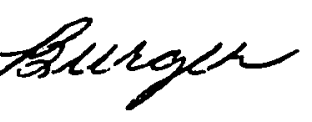

